\title{
Assisted Reproduction and Preterm Birth
}

\author{
Offer Erez ${ }^{1}$, Ruth Beer-Weisel ${ }^{1}$, Tal Rafaeli-Yehudai ${ }^{1}$, \\ Idit Erez-Weiss ${ }^{2}$ and Moshe Mazor ${ }^{1}$ \\ 'Department of Obstetrics and Gynecology "B" Soroka University Medical Center, \\ School of Medicine, Faculty of Health Sciences, \\ Ben Gurion University of the Negev, Beer Sheva, \\ ${ }^{2}$ Department of Family Medicine, School of Medicine, Faculty of Health Sciences, \\ Ben Gurion University of the Negev, Beer Sheva, \\ Israel
}

\section{Introduction}

Preterm parturition is a syndrome (Romero, Gomez et al., 1997; Romero R, Espinoza J et al., 2004) that is one of the leading causes for perinatal morbidity and mortality. Moreover, prematurity is a leading cause for neonatal mortality, as well as short and long term morbidity. The incidence of preterm delivery is constantly increasing, crossing the $12 \%$ in the USA, and it's annual cost reached 26.2 billion US dollars in 2005, posing a huge burden on public health (Institute of Medicine (US) Committee on Understanding Premature Birth and Assuring Healthy Outcomes, 2007).

Prematurity can be either spontaneous due to preterm labor with intact membranes (PTL) or preterm prelabor rupture of the chorioamniotic membranes (preterm PROM); or indicated, meaning induced preterm delivery by the medical team due to maternal (i.e. preeclampsia) or fetal (growth restriction, non-reassuring fetal heart rate tracing) indication (Goldenberg, Culhane et al., 2008). The incidence of the latter group, especially after 34 weeks of gestation, is constantly rising (Ananth, Joseph et al., 2005; Ananth and Vintzileos, 2006a; Ananth, Getahun et al., 2006).

Emerging contributors for the increasing rate of preterm birth are assisted reproduction technologies (Institute of Medicine (US) Committee on Understanding Premature Birth and Assuring Healthy Outcomes, 2007). The use of infertility treatments has risen dramatically in the past 20 years; between 1996 and 2003, the number of cycles of Assisted reproductive technologies (ART) nearly doubled from 64,681 to 122,872 . The number of live births resulting from conceptions achieved by the use of ARTs more than doubled from 14,507 to 35,785 (Institute of Medicine (US) Committee on Understanding Premature Birth and Assuring Healthy Outcomes, 1980). This has been associated with the trend to delay childbearing, indeed, more than 50 percent of these women were 35 years of age or older. In recent years, an unintended consequence of the use of these technologies, multiple gestations and the increased risk for preterm delivery, has become a focus of attention, and the institute of Medicine in the USA has concluded that "Fertility treatments are a significant contributor to preterm birth among both multiple and singleton pregnancies." (Institute of 
Medicine (US) Committee on Understanding Premature Birth and Assuring Healthy Outcomes, 2007).

The mechanisms in which assisted reproduction technologies increases the risk for preterm birth are still under investigation. Aside the contribution of ART to the increase number of multiple gestations (especially twins) that increases the risk for preterm delivery; The mechanisms leading to preterm delivery in singleton gestations conceived through ART have not been thoroughly investigated. Preliminary evidence suggests that some of the underlying maternal conditions that lead to infertility (i.e. inflammation and insulin resistance) may contribute to this observation.

The current chapter will explore the epidemiology, underlying mechanisms, and possible tools for the prevention of preterm delivery in pregnancies conceived by assisted reproduction.

\section{Infertility: Treatments, epidemiology and trends}

\subsection{Definitions}

The most commonly used definition of infertility is a failure to conceive after 12 months of regular, unprotected intercourse. However, existing definitions of infertility lack uniformity, rendering comparisons of prevalence between countries or over time problematic. The absence of an agreed definition also compromises clinical management and undermines the impact of research findings. Gurunath at al suggested that the definition will be based on the duration of trying for pregnancy coupled with female age. (Gurunath, Pandian et al., 2011) According to the report of The Centers for Disease Control and Prevention (CDC), in $2002,7 \%$ of married couples in which the woman was of reproductive age (2.1 million couples) reported that they had not used contraception for 12 months and the woman had not become pregnant. Many of these patients are treated by ARTs. These technologies are defined by the CDC as procedures in which the ovum and the sperm are handled in the laboratory. During the past few decades several options of ART have developed including: 1) in vitro fertilization (IVF); 2) intra-cytoplasmic sperm injection (ICSI); 3) gamete intrafallopian transfer (GIFT) and 4) zygote intra-fallopian transfer (ZIFT) (Centers for Disease Control and Prevention 2008).

\subsection{What is the magnitude of ART utilization in developed countries?}

The use of infertility treatments has risen dramatically in the past 10 years and has been associated with the trend to delay childbearing. Today, over $1 \%$ of all infants born in the United States every year are conceived using ART; and the number of ART cycles performed has nearly doubled, from 87,636 cycles in 1999 to 148,055 in 2008. Similarly, the number of live-birth in $2008(46,326)$ was more than twice the number recorded 1999 $(21,746)$. Because in many of the ART pregnancies more than one infant is born alive (e.g., twins, triplets), the total number of infants born is greater than the number of live-birth. The trend in the number of infants delivered after ART cycles was in accord to the trends observed in the number of pregnancies and live-births. Thus, the number of infants born in 2008, $(61,426)$ was more than twice than the 30,629 that were delivered in 1999 (Figure 1).

Outside the USA, The Canadian Assisted Reproductive Technologies Register (CARTR), in its 2007 annual publication, reported a 12\% increase in the total number of ART cycles, and an increase in the rate of clinical pregnancies and live-birth, along with a decrease in highorder multiple births in comparison to these parameters in 2006 (Gunby, Bissonnette et al., 
2011). While in Europe, according to the 10th annual European Society of Human Reproduction and Embryology (ESHRE) publication the reported number of ART cycles has increased, with a marginal increase in pregnancy rates, even though fewer embryos were transferred and the multiple delivery rates have declined (1994). This report includes 20 countries, where all clinics report their activity to the IVF register. Altogether, a total of 359,110 cycles were performed in a population of 422.5 million, corresponding to 850 cycles per million inhabitants. The IVF cycles rates of clinical pregnancy per ovum aspiration and per embryo transfer were 29.0 and $32.4 \%$, respectively; while the corresponding ICSI cycles rates were 29.9 and $33.0 \%$, respectively (1994). In spite of the new guidelines, transferring of 2 embryos is still the most prevalent choice in the European Union.

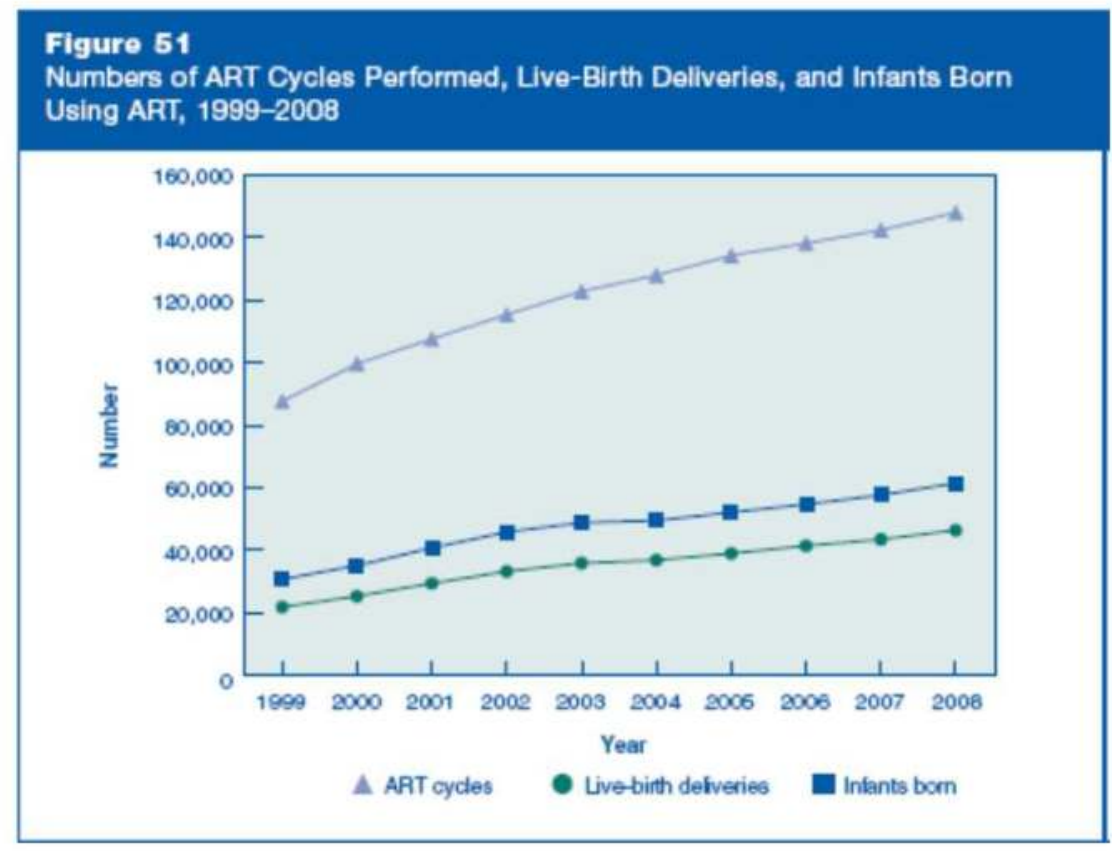

Fig. 1. Number of ART cycles performed, live-birth delivery, and infants born used ART, 1999-2008 From Centers for Disease Control and Prevention, American Society for Reproductive Medicine, Society for Assisted Reproductive Technology. 2006 Assisted Reproductive Technology Success Rates: National summary and fertilityNclinic reports. Atlanta: Centers for Disease Control and Prevention,2008.

ART often is categorized according to whether the procedure used a woman's own eggs (self) or eggs from another woman (donor) and according to whether the embryos used were newly fertilized (fresh) or previously fertilized, frozen, and then thawed (frozen). For approximately $71 \%$ of ART cycles performed in USA in 2008, self-fresh eggs or embryos were used. ART cycles that used self-frozen embryos were the next most common type, accounting for approximately $17 \%$ of the total. In about $12 \%$ of cycles, eggs or embryos were donated by another woman (Figure 2). 


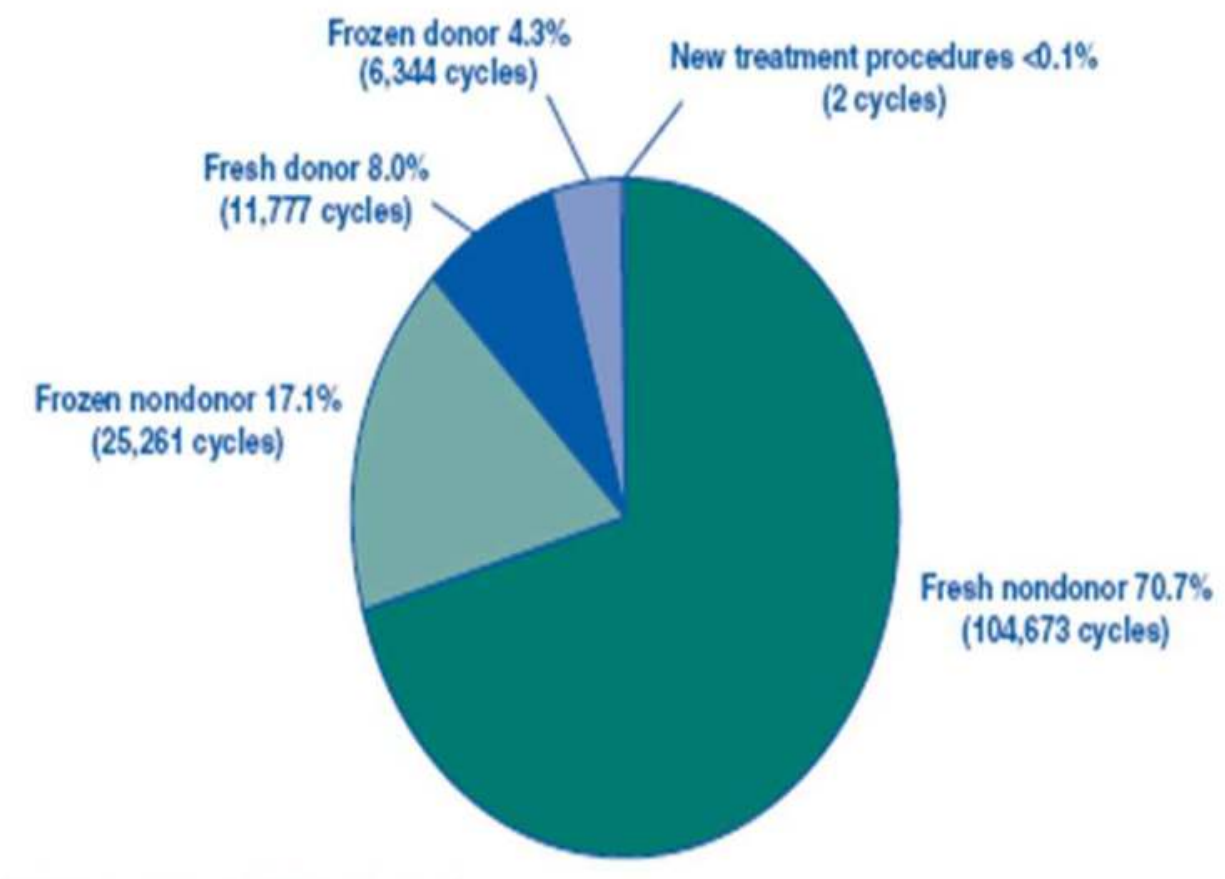

'Tctal does not equal 100\% dus b roundng.

Fig. 2. Distribution of ART cycles according to the source of the ovum and whether the cycle was fresh or frozen. (CDC 2008, USA).

The average age of women using ART services in the USA in 2008 was 36 . However, the largest group of women using ART services were women younger than 35, representing approximately $39 \%$ of all ART cycles performed in 2008. Approximately $21 \%$ of ART cycles were performed in women aged 35-37, 20\% in women aged 38-40, 10\% in women aged $41-42,6 \%$ in women aged $43-44$, and 5\% among women older than 44 ( Figure 4 ). In Europe, the age distribution of women treated with IVF varied across the continent. In some countries, more than $20 \%$ of women were aged 40 years or older (Greece, Ireland, Italy, Macedonia, Montenegro, Serbia and Switzerland), whereas in Bulgaria, Czech Republic, Lithuania, Norway, Poland, Portugal, and Ukraine $<10 \%$ were 40 years or older. (ESHRE,2006)

The success rate of ART decreases with age, indeed, pregnancy rates decreased from $28.2 \%$ in women aged $\leq 34$, to $9.6 \%$ at the age $\geq 40$ years. A similar trend was seen for the delivery rates $(26.6 \%$, and $8.6 \%)$. In egg donation cycles, the recipients were aged 40 years or more in $50.0 \%$ of cases, in almost all countries. Pregnancy and delivery rates in oocyte recipients were comparable across different age groups. (ESHRE,2006) 


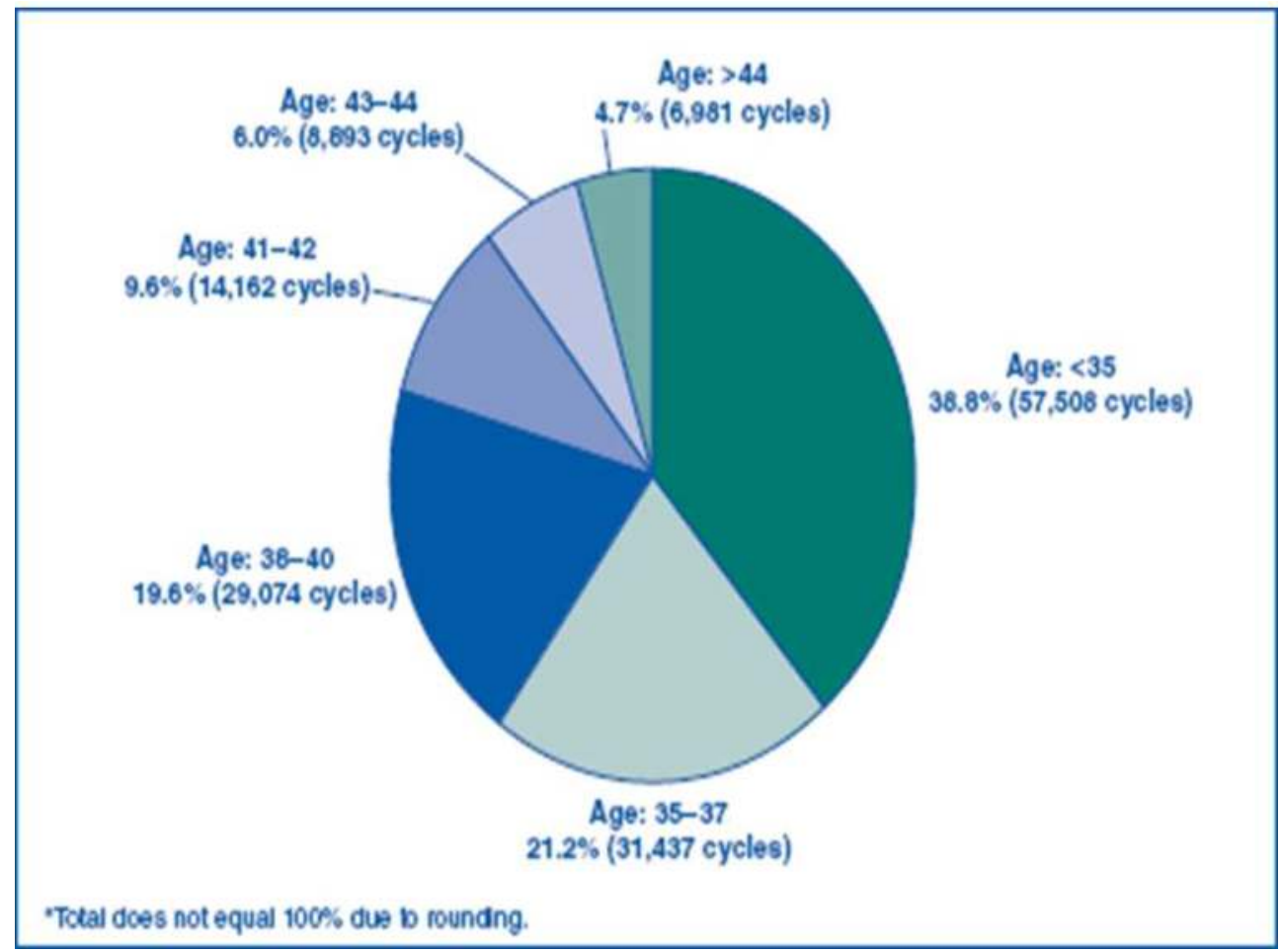

Fig. 3. Maternal age distribution among patients undergoing ART cycles. CDC 2008 USA.

\section{The effect of maternal age on reproduction and pregnancy outcome}

The average fertility rate (live births per 1,000 women of childbearing age 15-44 years) in USA from 1991-2008 is about 66.5, with mild fluctuations over the years. When it is divided in subgroups by maternal age, the birth rate has declined for women under 30-s on the other hand among women in their 30's- 40's the fertility rate had steadily increased from 1978 onward. In the last three decades a new group of women aged 50 and over has increased more than 10 percent annually since 1997 (Martin, Hamilton et al., 2010). The trend in the fertility rate among European women is somewhat different. From the 1960s up to the beginning of the 21st century, the number of live births in the Europe declined sharply. However, from 2002 onward there has been a modest rebound in the number of live births born in this continent. As with the American women, the late increase during the last years may be, in part, attributed to a catching-up process following a general pattern of postponing the child bearing age. When women give birth later in life, the total fertility rate first indicates a decrease in fertility, followed later by a recovery (Atkinson and Marlier, 2010). For example, in Finland the rate of women giving birth after the age of 35 increased from $16.7 \%$ in 1997 to $19.2 \%$ in 2007 (Lampinen, Vehvilainen-Julkunen et al., 2009). The corresponding mean maternal age in Japan between 1970 and 2000 increased from 25.6 to 28.0 years (Mathews and Hamilton, 2002). 
Delaying childbearing may be attributed to several reasons, beginning with the longer life span, greater accessibility to education and career opportunities for women, and the existence of effective means of birth control (Stein, 1985; Berkowitz, Skovron et al., 1990). Men and women recognized the direct relationship between older maternal age and the declined in fertility (Tough, Benzies et al., 2006; Tough, Benzies et al., 2007), however, there is a popular concept that IVF treatment can reverse the effects of age (Maheshwari, Porter et al., 2008). Interestingly, along with acknowledgment in the success of ART there is a lack of awareness regarding the effect of maternal age over perinatal complications during pregnancy. Women are not aware of the increased risk of preeclampsia, stillbirth, caesarean delivery, multiple births and preterm delivery associated with delayed childbirth to elderly stages of life (Tough, Benzies et al., 2006; Tough, Benzies et al., 2007).

Postponement of motherhood beyond 35 years of age influences many aspects of reproduction from conceiving through embryonic implantation all the way until delivery. The effect of maternal age on her ability to conceive is well documented. Populations that do not use contraceptives and practice unprotected intercourse give the best estimation of the ability of normal women to conceive. Based on 10 different populations living between the 17th and the 20th Centuries that did not use contraceptives, Menken et al (Menken, Trussell et al., 1986) reported that the fertility rate remains relatively stable until a woman is in her late 30s and then decreases substantially from more than 400 pregnancies per 1000 women per year at the age of 30, to only 100 pregnancies per 1000 women per year by the age of 45 . The decline in fertility as a function of women's age was also demonstrated in a donor insemination programmed in which the cause of infertility was related to male factors alone and the women were assumed to be normal. Pregnancy rates at 1 year declined from $74 \%$ among women below the age of 30 years to $61.5 \%$ among women aged 31-35 years and $55.8 \%$ among women aged 36-41 years (Schwartz and Mayaux, 1982).

After conceiving, the risk of spontaneous miscarriage increases as a function of maternal age. In a prospective population-based register linkage study, involving 12,221,546 pregnancies of 634,272 Danish women from 1978 to 1992, older maternal age was a significant risk factor for spontaneous pregnancy loss irrespective of the number of previous miscarriages and parity. The risk of a spontaneous abortion in women aged 20-24 years was $8.9 \%$ and it climbed up to $74.7 \%$ in those aged 45 years or older (Nybo Andersen, Wohlfahrt et al., 2000). Ben Kroon et all performed a cytogenetic evaluation for the products of conception obtained from patients with first trimester abortion who had a dilatation and curettage $(D \& C)$. The rate of embryos with aneuploidy in women aged $\geq 35$ years was significantly higher than that of those younger than 35 years $(45.7 \%$, vs. $34.8 \%$, respectively; $\mathrm{P}=.018$ ) (Kroon, Harrison et al., 2011). The derived rates apply to women whose only risk factor is advanced maternal age. The categories analyzed were trisomy 21 (Down's syndrome), Trisomy 18 (Edwards' syndrome), trisomy 13 (Patau's syndrome), 47XXY (Klinefelter's syndrome), 47,XXX, and a group of other clinically significant abnormalities that were considered collectively. The rate of all these chromosomal abnormalities in this study was about five per 1,000 at age 35 years, 15 per 1,000 at age 40 years, and 50 per 1,000 at age 45 years (Hook, Cross et al., 1983). Savva et al (Savva, Walker et al., 2010) reviewed the records of prenatal and postnatal diagnoses from seven UK regional congenital anomaly registers and two Australian registers from 1997 to 2004. These dataset included 4.5 million deliveries, of which 975 diagnosed as having trisomy 13 and 2254 had trisomy 18. In addition, the authors reported that since 1989 until 1996 there was an increase, by $13 \%$ in the 
rate of trisomy 13 and by $25 \%$ in the rate of trisomy 18 . These findings are consistent with those predicted to be associated with the increases in maternal age (Savva, Walker et al., 2010).

The link between Down syndrome and advanced maternal age deserves special attention. This association was already reported by Penrose in the mid 1930's (Penrose, 1933; Penrose, 1934). Lately, Graves Allen et al (Allen, Freeman et al., 2009) examined the origin of the meiotic error leading to the association between maternal age and chromosome 21 nondisjunction. They emphasis that the a significant association between advanced maternal age and chromosome 21 non-disjunction was restricted to meiotic errors in the egg and was not observed in sperm or in post-zygotic mitotic errors. The authors reported that the advanced maternal age was significantly associated with a higher rate of non-disjunction in both meiosis I (MI) and meiosis II (MII). Indeed, compared to mothers of euploid neonates, mothers of infants with trisomy 21 due to MI non-disjunction were 8.5 times more likely to be $\geq 40$ years old than $20-24$ years old at the birth of the index case (95\% CI $=5.6-12.9$ ). Where non-disjunction occurred in MII, mothers were 15.1 times more likely to be $\geq 40$ years (95\% CI = 8.4-27.3) (Allen, Freeman et al., 2009).

Women's age has a major impact on the rate of chronic maternal diseases and pregnancy outcome. Indeed, the rate of diabetes increases with maternal age. The 2010 National Vital Statistics Reports reported that in 2007 the rate of diabetes among USA mothers under the age of 20 was 14.0 per 1,000, and it increases almost 7 times higher to 100.5 per 1,000 in women over the age of 40 (Table 1). Similar trends were reported regarding the rate of chronic hypertension. The prevalence of this disease increases from 3.9 per 1000 in women younger than 20 years old to 32.2 per 1000 in women older than 40 . In contrast to the linear association between diabetes, as well as chronic hypertension and maternal age, the incidence of gestational hypertension as a function of maternal age has a $U$ shape curve with a prevalence of 41.8 per 1000 among patients under 20 years and 50.1 per 1000 for women over 40, and the lowest incidence is between 20-35 years old. Similarly to the National Vital Statistics Reports, a different population based cohort involving 1,160,000 women delivered during a 2-year period found increased rate of preeclampsia and gestational diabetes among women aged 40 years or older in comparison to those aged 20-29 (Gilbert, Nesbitt et al., 1999). Yogev et al (Yogev, Melamed et al., 2010) stratified the rate of pregnancy complication according to maternal age with a special attention to women aged $\geq 45$ years $(n=177)$ with an additional subgroup analysis of women aged 45-49 years with those women aged $\geq 50$ years. Similar to previous studies the authors reported that the rates of gestational diabetes mellitus and hypertensive complications of pregnancy were increased among women aged 45 years and older.

Maternal age also influences perinatal outcome, small-for-gestational age births (SGA) are common and can have serious immediate consequences for the infant (Das and Sysyn, 2004; Salem, Levy et al., 2011). They have also been associated with the development of a range of chronic diseases in subsequent adult life (Nepomnyaschy and Reichman, 2006; Barker, 2004). There is an association between maternal age and the delivery of an SGA neonate. In the FASTER trial, patients aged 35-39 years were at increased risk to a deliver low birthweight neonate (adjusted OR 1.6) (Cleary-Goldman, Malone et al., 2005). In addition, Salem- Yaniv et al, in a retrospective population based study found a significant increase in low birth weight among older women (35-40 and above 40 years of age) in comparison to women younger than 35 years old (Salem, Levy et al., 2011). 


\begin{tabular}{|c|c|c|}
\hline Maternal age & $\begin{array}{c}\text { Diabetes per 1,000 } \\
\text { live births in } \\
\text { specified group }\end{array}$ & $\begin{array}{c}\text { Chronic Hypertension per 1,000 } \\
\text { live births in specified group }\end{array}$ \\
\hline All ages & 44.8 & 11.0 \\
\hline Under 20 years & 14.0 & 3.9 \\
\hline $20-24$ years & 25.9 & 6.4 \\
\hline $25-29$ years & 42.4 & 13.6 \\
\hline $30-34$ years & 59.5 & 20.4 \\
\hline $35-39$ years & 78.6 & 32.2 \\
\hline $40-54$ years & 100.5 & 9.9 \\
\hline
\end{tabular}

Table 1. Number and rate of live births to mothers with selected risk factors during pregnancy, obstetric procedures, characteristics of labor and delivery, and congenital anomalies, by age and race and Hispanic origin of mother: United States, 2007. (National Vital Statistics Reports, Volume 58, Number 24, August 9, 2010)

The Human Fertilization and Embryology Authority database was examined in order to ascertain the predictors of live birth in all IVF cycles undertaken in the UK between 2003 and 2007 ( $n=144,018)$. This study has found that the odds of low birth weight were reduced with increasing maternal age and with a history of a previous pregnancy (either spontaneous or following IVF) (Nelson and Lawlor, 2011). Similarly to these findings, Erez et al reported that among patients with twin gestation who conceived through ART the rate of preeclampsia was higher in women younger than 35 years old than in older parturient (Erez, Vardi et al., 2006). These reports suggest that among patients who suffers from infertility the background maternal illness may be more severe and with clinical implication that is additive to the effect of maternal age.

Advanced maternal age also influences the rate of preterm delivery. Jacobsson et al examined the Swedish Medical Birth Register, managed by the National Board of Health and Welfare, contains data on 1,566,313 deliveries that are more than $99 \%$ of all births in Sweden during the last 15-years. The rate of preterm delivery before 37 and 34 weeks among women 20-29 were compared to those of women age 40-44 years and above 45 years (Jacobsson, Ladfors et al., 2004). The authors reported that the rate of preterm birth increases with maternal age. Indeed, after adjustment to confounding factors women aged 40-44 years old had an odds ratio of 1.54 (95\% CI 1.47-1.60), while those who were $\geq 45$ years had an odds of 1.63 (95\% CI 1.32-2.00) to deliver before 37 weeks of gestation (Jacobsson, Ladfors et al., 2004). Similar data where published also by others (ClearyGoldman, Malone et al., 2005; Salem, Levy et al., 2011). 
Women $\geq 35$ years have a significantly higher rate of fetal death than their younger counterparts. Fretts and colleagues documented that the fetal death rate decreased by more than 70 percent over the past 30 years among white Canadian women. Although the absolute stillbirth rate declined significantly for women of all ages and parity groups, older women remained at higher risk for fetal death, even after controlling for diabetes, hypertension, and placental abruption (Fretts, Schmittdiel et al., 1995). This report was in accord with other publications regarding the increased rate of fetal demise among older women (Jacobsson, Ladfors et al., 2004; Cleary-Goldman, Malone et al., 2005). In contrast, among nulliparous patients advanced maternal age was not an independent risk factor for perinatal mortality (Salem, Levy et al., 2011).

The increasing numbers of pregnancies at advanced maternal age influences the rising rate of cesarean birth. Among 57,426 primiparous women who gave birth in Victoria, Australia, in 2005 and 2006, older patients were more likely to give birth by cesarean section in comparison to younger primiparous women (Carolan, Davey et al., 2011). Salem-Yaniv at al reported that in comparison to women younger than 35 years old, those aged 35-40 have an almost a threefold increase in the rate of cesarean deliveries among nulliparous patients $(38.2 \%)$ and close to a fivefold increase among women over 40 years (63.3\%) (Salem, Levy et al., 2011). Similar results were published by the National Vital Statistics Reports UA. Among $4,316,233$ women that delivered during the year 2007, older maternal age was associated to delivery through cesarean section (under 20 22.7\% 35-39 41.8\%: 40-54 47.7\%) (Martin, Hamilton et al., 2010). This increasing risk of cesarean birth associated with advancing maternal age is of importance, because the proportion of women who are delaying childbearing is growing, and in addition, the cesarean delivery rate is increasing (Martin, Hamilton et al., 2010).

\section{Pregnancy outcome in patients conceived through assisted reproduction}

IVF pregnancies are associated with an increased risk for obstetrics complication including gestational diabetes, preeclampsia, placenta previa and neonatal intensive care admission (Shevell, Malone et al., 2005; Chen, Wen et al., 2009; Nelson and Lawlor, 2011). A prospective database from a large multicenter investigation of singleton pregnancies demonstrated that the use of IVF was associated with a significant increase in the risk to develop preeclampsia (OR 2.7; 95\% CI 1.7-4.4), placental abruption (OR 2.4; 95\% CI 1.1-5.2), placenta previa (OR 6.0; 95\% CI 3.4-10.7), and risk of cesarean delivery (OR 2.3; 95\% CI 1.8-2.9) (Shevell, Malone et al., 2005). A different prospective cohort study that included singleton IVF/ICSI pregnancies had more than 4 -fold increased risk of stillbirth compared with spontaneously conceived singleton pregnancies (Wisborg, Ingerslev et al., 2010a). There is a strong evidence to support the association between IVF treatments and preterm birth. Indeed, ART are independently associated with preterm birth in singleton as well as in twin gestation.

\section{The association between preterm birth and assisted reproduction}

Preterm delivery is the leading cause for perinatal morbidity and mortality worldwide (Goldenberg, Culhane et al., 2008). The annual societal economic burden associated with preterm birth in the United States exceeded \$26.2 billion in 2005 (Institute of Medicine (US) Committee on Understanding Premature Birth and Assuring Healthy Outcomes, 2007). Preterm birth is associated with short and long term maternal and fetal sequel. The 
mothers are at risk of recurrent preterm birth and cardiovascular disease later in life. (Nardi, Zureik et al., 2006; Smith, Pell et al., 2001) The premature newborn is at risk for acute (i.e. respiratory distress syndrome, necrotizing enterocolitis, and intraventricular hemorrhage) and chronic (i.e. retinopathy of prematurity, cerebral palsy, broncho pulmonary dysplasia) illness, as well as social and behavioral maladjustment later in life. (Moster, Lie et al., 2008) The prevalence of preterm birth varies from $6 \%$ to $15 \%$ of all deliveries depending on the geographical and demographical characteristics of the population tested. (Romero, Mazor et al., 1994; Martin, Hamilton et al., 2009; Slattery and Morrison, 2002).

In Europe the rate of preterm deliveries varies from 5\% to 9\% (Slattery and Morrison, 2002), while the rate of preterm birth in the United States reached 12.8\% by 2006 (Martin, Hamilton et al., 2009), 20\% higher than in 1990. Of interest, while the rate of early ( $<34$ weeks) preterm birth remained relatively constant $(2.9 \%$ among singleton and $3.3 \%$ to $3.6 \%$ among multiple gestations) the rate of late preterm birth (34-37 weeks) increased among singleton by $19.1 \%$ (from $6.1 \%$ to $8.1 \%$ ) and by $24.7 \%$ among all pluralities from 1990 to 2005 (Martin, Hamilton et al., 2007) (Figure 4).

Preterm delivery can be either spontaneous or medically induced (indicated) regardless of the gestational age at delivery. Spontaneous preterm birth account for $75 \%$ of all preterm deliveries (Meis, Ernest et al., 1987; Meis, Goldenberg et al., 1998; Meis, Michielutte et al., 1995) and can be the end result of three main clinical presentations: 1) preterm labor with intact membranes; 2) preterm prelabor rupture of membranes (preterm PROM); and 3) cervical insufficiency. (McElrath, Hecht et al., 2008) Indicated preterm birth results from medical intervention due to maternal or fetal complications that necessitate medical intervention. (Ananth and Vintzileos, 2006b; Mazaki-Tovi, Romero et al., 2007; Meis, Michielutte et al., 1995; Ananth and Vintzileos, 2006a; Ananth, Getahun et al., 2006) Although many studies have focused on the rate of preterm birth, (1999; Joseph, Kramer et al., 1998; Vintzileos, Ananth et al., 2002) an important consideration is whether these deliveries are the result of spontaneous labor or "indicated" preterm deliveries. The need for this distinction is based on the premise that the risk factors for recurrent preterm PROM, preterm labor with intact membranes, preeclampsia, and/or SGA are different. However, recent observations suggest that there may be overlap among these conditions, (Ananth and Vintzileos, 2006a; Ananth, Getahun et al., 2006) so that a patient with an "indicated" preterm birth may also be at risk for spontaneous preterm birth (Ananth and Vintzileos, 2006a; Ananth, Getahun et al., 2006). The converse may also be true (i.e. that a patient with a spontaneous preterm birth is at risk for an "indicated" preterm birth in a subsequent pregnancy).

Assisted reproduction technologies are emerging contributors for the increasing rate of preterm birth. The use of infertility treatments has risen dramatically in the past 20 years; between 1996 and 2003, the number of cycles of ART nearly doubled from 64,681 to 122,872 (Institute of Medicine (US) Committee on Understanding Premature Birth and Assuring Healthy Outcomes, 2007). The number of live births resulting from conceptions achieved by the use of ARTs more than doubled from 14,507 to 35,785. This has been associated with the trend to delay childbearing, indeed, more than 50 percent of these women were 35 years of age or older. In recent years, an unintended consequence of the use of these technologies, multiple gestations and the increased risk for preterm delivery, has become a focus of attention. Indeed, the institute of Medicine in the USA has concluded that "Fertility 
treatments are a significant contributor to preterm birth among both multiple and singleton pregnancies." (Institute of Medicine (US) Committee on Understanding Premature Birth and Assuring Healthy Outcomes, 2007).

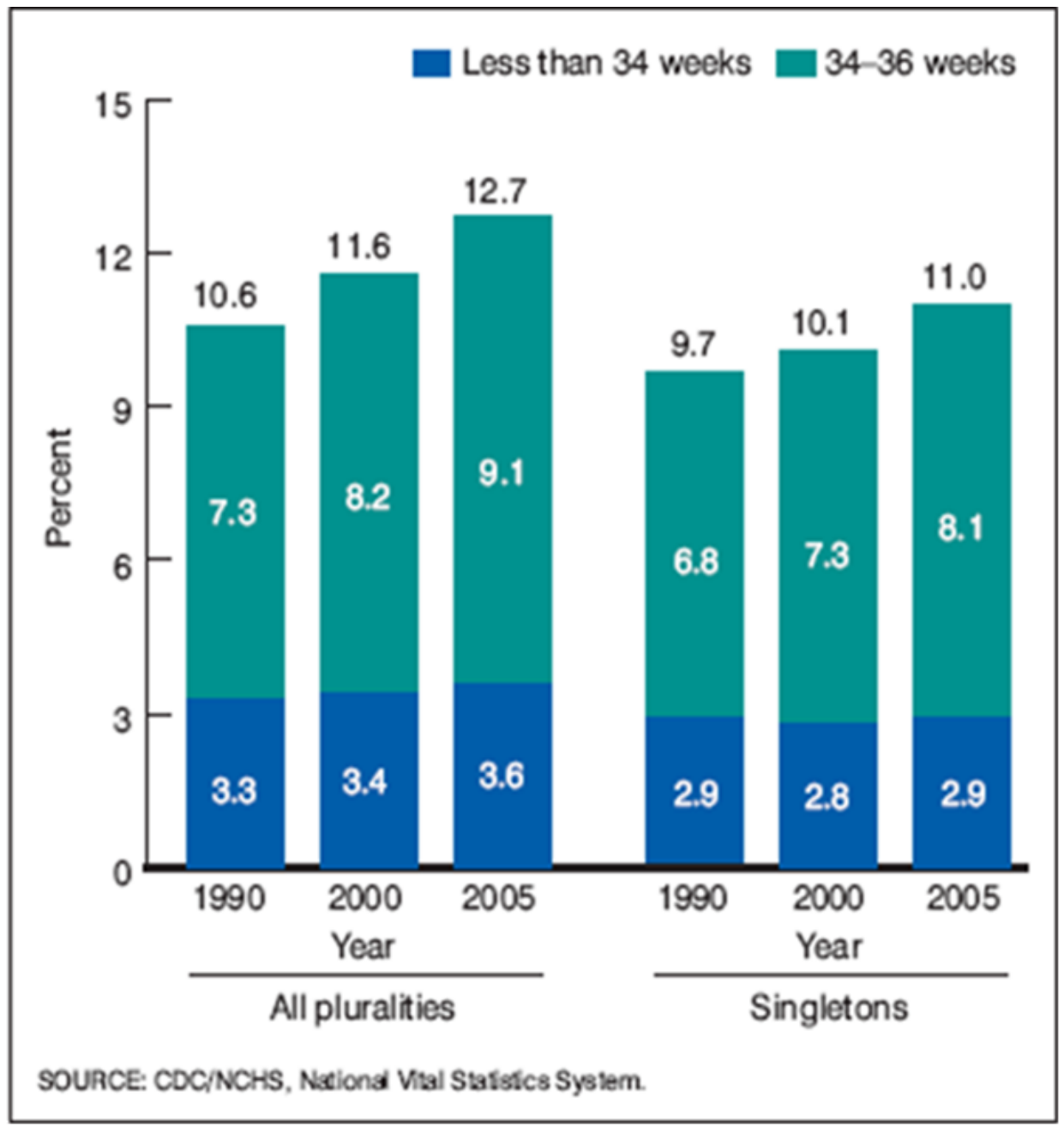

Fig. 4. Chances over time in the rate of preterm birth according to gestational age at delivery and the number of fetuses.

ART are associated with increased rate of pregnancy complication. Several questions are being raised in regard with this topic:1) what are the causes or mechanisms leading for such complications? Is it the treatment or the underlying maternal condition that leads to infertility? 2) Are these complications due to multiple gestation or they affect also singleton gestations? 3) Is there an association with between the ART protocol and adverse pregnancy outcome? 


\subsection{The association between ART and multiple gestations}

There is a direct relationship between the rise in the use of assisted reproduction and the increasing rate of multiple gestations. This trend is mostly due to the transfer of multiple embryos. In spite of the new regulation regarding the maximal embryos transferred during IVF cycle. In 2008, among the ART cycles that used fresh non-donor eggs or frozen-thawed embryos and progressed to the embryo transfer stage, approximately 38\% involved the transfer of three or more embryos, about $13 \%$ of cycles involved the transfer of four or more embryos, and approximately $4 \%$ of cycles involved the transfer of five or more embryos. In addition, ART conceived pregnancies have a higher rate of zygotic splitting in cycles were a single embryo was transferred resulting in increased rate of monochorionic twins than spontaneously conceived pregnancies (Blickstein, Jones et al., 2003; Blickstein, Verhoeven et al., 1999). Among the 38,631 pregnancies that resulted from ART cycles using fresh nondonor eggs or embryos, approximately $61 \%$ were singleton, $29 \%$ were twins, and about $4 \%$ were triplets or more. Approximately $32 \%$ of the pregnancies ending in live births produced more than one infant ( $30 \%$ twins and approximately $2 \%$ triplets or more). This compares with a multiple-infant birth rate of slightly more than $3 \%$ in the general U.S. population Figure 5.

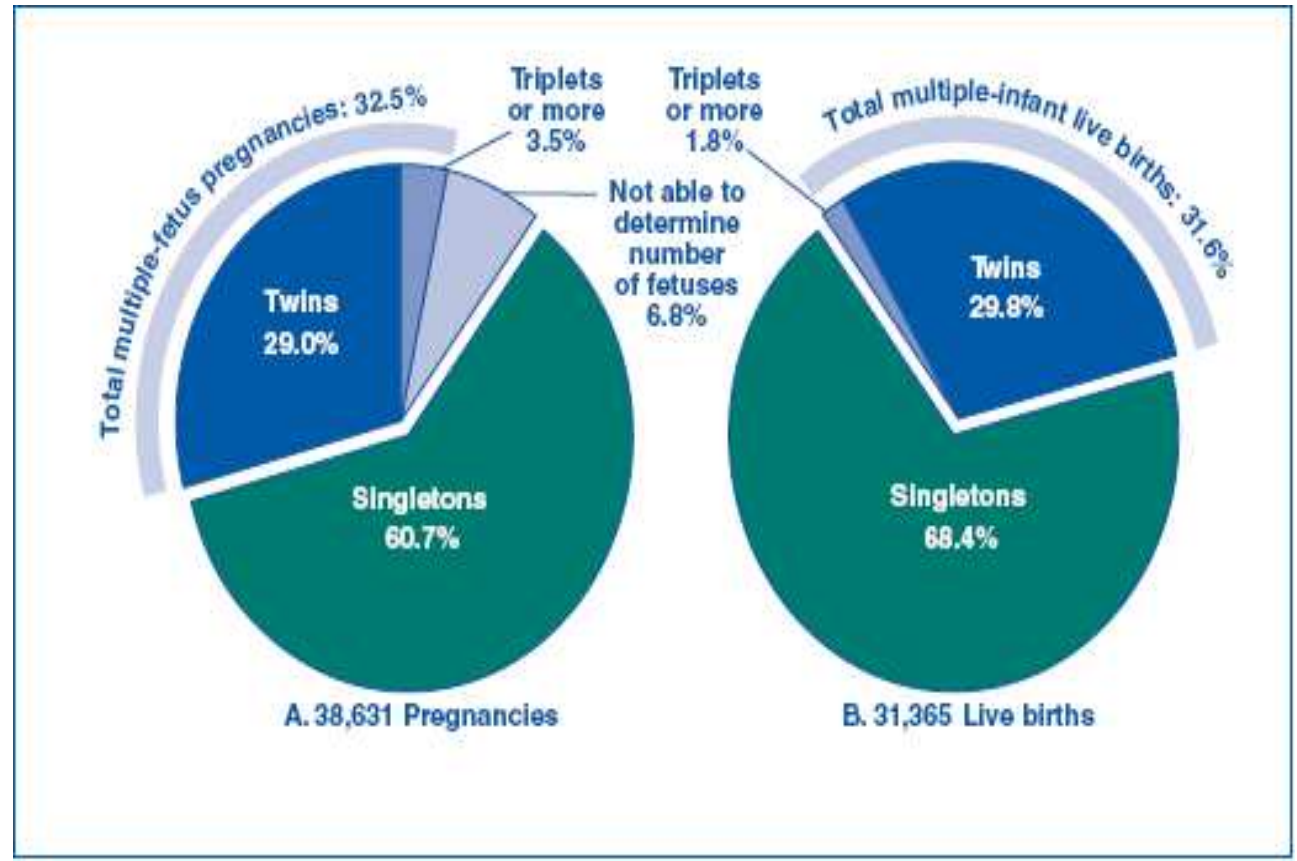

Fig. 5. Risk of having multi-frtus pregnancies and multiple infant live birth from ART cycles using fresh non-donor eggs or embryos-US CDC 2008.

The proportions of multiple birth in Europe is lower than in the USA, and is declining in the recent years. Indeed, the proportion of singleton, twin and triplet deliveries after IVF and ICSI combined was 79.2, 19.9 and $0.9 \%$, respectively. This gives a total multiple delivery rates of $20.8 \%$ compared with $21.8 \%$ in 2005 and $22.7 \%$ in 2004 (ESHRE, 2006). In 
an effort to reduce the number of higher-order multiple pregnancies, the American society for reproductive medicine (ASRM) and the Society for Assisted Reproductive Technology Data (SART) have developed guidelines for the number of embryos to be transferred in IVF cycle.

\subsubsection{What is the effect of the mode of conception on the risk for preterm birth in twin gestations?}

Twin and higher order of multiple gestation are at increased risk to deliver preterm. Nevertheless, the effect of mode of conception on the prematurity rate in twin pregnancies is under continues debate. Several studies have stated that twin pregnancies conceived through ART have similar perinatal complication rate (Zaib-un-Nisa, Ghazal-Aswad et al., 2003; Boulet, Schieve et al., 2008). In contrast, other studies and number of meta-analysis demonstrated no difference between spontaneously and ART conceived twin (Daniel, Ochshorn et al., 2000; Wright, Schieve et al., 2003; Wright, Schieve et al., 2004; Wang, Sullivan et al., 2005; Pinborg, 2005; Allen, Wilson et al., 2006; Reddy, Wapner et al., 2007; Chan, Mannino et al., 2007; A B and M K, 2008; Shebl, Ebner et al., 2009; Hansen, Colvin et al., 2009; Weghofer, Klein et al., 2009; Rossi and D'Addario, 2011; Morcel, Lavoue et al., 2010). Verstraelen et al reported in a population based cohort study, that pregnancies conceived by ART have a persistent increased risk for preterm delivery (Figure 6), even after correction for birth year, maternal age, parity, and for infant sex, caesarean delivery, zygosity, and chorionicity (Verstraelen, Goetgeluk et al., 2005).

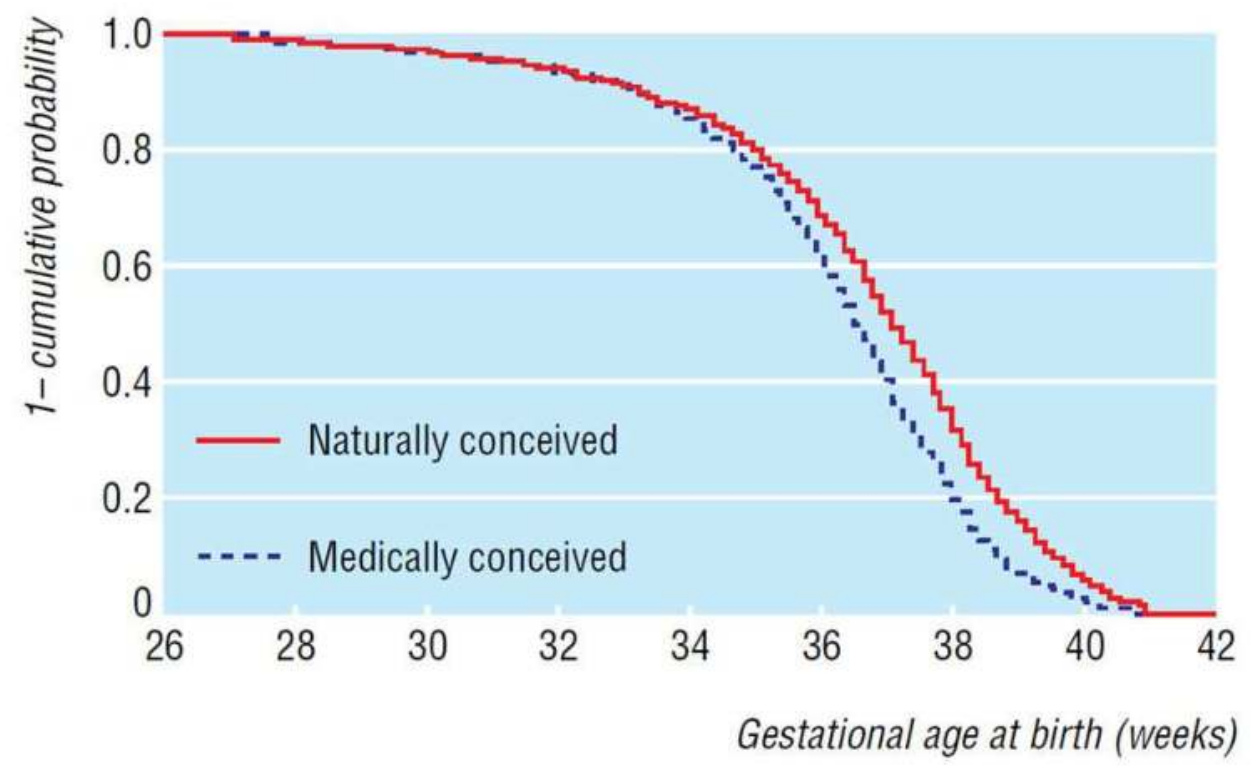

Fig. 6. Kaplan-Meier plot of gestational length in naturally conceived $(n=2915)$ and medically conceived $(n=1453)$ twins. Adopted from Verstraelen H et al. BMJ, 2005; 331: 1173.with permeation. 
In addition, Erez et al in a population based cohort study reported that ARTs are an independent risk factor for preterm birth after adjustment to parity, rupture of membranes, severe preeclampsia (Erez, Mayer et al., 2008). In a systematic review and meta-analysis including eleven case-control studies that involved 2303 IVF twins and 2326 spontaneously conceived twins, as well as, three cohort studies that involved at least 1509 IVF twins IVF twins have an increase risk for PTB from 32 to 36 weeks of gestation compared with spontaneously conceived twins who were matched for maternal age (OR, 1.48; 95\% CI, 1.052.10). The OR for PTB at $<37$ weeks of gestation in studies that also matched for parity was similar and approached statistical significance at a 5\% level of significance (OR, 1.47; 95\% CI, 1.01-2.44). The origin of the increase in PTB has yet to be determined (McDonald, Han et al., 2010). Collectively these studies suggest that in comparison to spontaneously conceived twin gestations, twin pregnancies that result from ART are at increased for preterm birth especially between 32-36 weeks of gestation.

\subsection{Are singleton ART pregnancies at increased risk for preterm birth?}

One of the major questions regarding the association between ART and preterm birth was whether this effect is mainly due to the increase in the rate of multiple pregnancies or is it relevant also for singleton gestations (Jackson, Gibson et al., 2004; McGovern, Llorens et al., 2004; Schieve, Meikle et al., 2002). Mounting evidence suggest that singleton pregnancies conceived following ART are at increased risk for preterm birth. Indeed: 1) In a Prospective follow-up study done in Denmark, including a total of 20,080 liveborn singletons, in comparison to fertile women, those who conceived following IVF/ICSI had a significant increase in the risk of preterm and very preterm delivery (Wisborg, Ingerslev et al., 2010b). 2) Schieve et al compared the outcome of 62,551 infants born after ART treatments performed in 1996-2000. Secular trends in low birth weight (LBW), very low birth weight (VLBW), preterm delivery, preterm LBW, and term LBW were examined. Detailed analyses were performed for 6,377 infants conceived in 2000. Observed numbers were compared with expected using a reference population from the 2000 U.S. natality file. Singleton infants born after ART in 2000 had elevated risks for all outcomes in comparison with the general population of U.S. singletons: LBW standardized risk ratio 1.62 (95\% CI 1.49, 1.75), VLBW 1.79 (95\% CI 1.45, 2.12), preterm delivery 1.41 (95\% CI 1.32, 1.51), preterm LBW 1.74 (95\% CI 1.57, 1.90), and term LBW 1.39 (95\% CI 1.19, 1.59) (Schieve, Meikle et al., 2002). 3) In a USA population based surveillance, singletons of mothers who received ART procedures were more likely to be born preterm, with low birthweight, and SGA than singleton infants conceived spontaneously. 4) A meta-analysis revealed that singletons born following IVF are twice as likely to be delivered preterm and die within 1 week of birth compared with the risk of those conceived spontaneously (McGovern et al., 2004). 5) Singletons conceived through the use of IVF are twice as likely to be born preterm and die within 1 week of birth as those not conceived through IVF and 2.7 times more likely to have a low birth weight (Hampton, 2004). 6) A meta-analysis that compiled information from 12,283 singleton births resulting from IVF pregnancies and 1.9 million spontaneously conceived singleton births noted a twofold increase in the risk of preterm delivery (Jackson et al., 2004). 7) According to the CDC report among the infants conceived through the use of ART, singletons that resulted from fetal reduction (either spontaneous or medically) had a higher rate of preterm birth $(19 \%)$ than those who started as a singleton gestation (12\%) (Figure 7). 


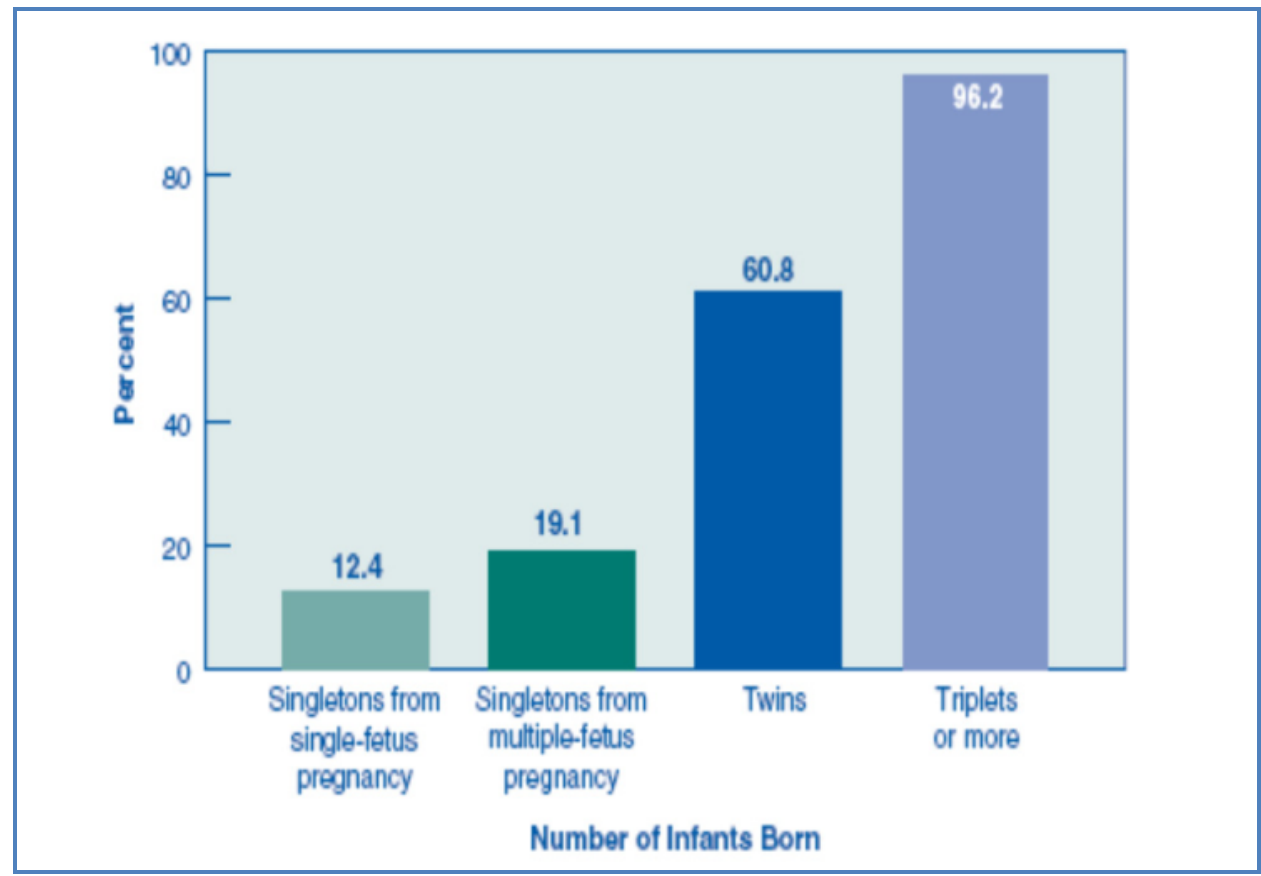

Fig. 7. Proportion of preterm birth resulting from ART cycles using fresh non-donor eggs or embryos, by number of infants born-USA, CDC 2008.

\subsection{What are the possible mechanisms associated with the increased risk for preterm birth in ART pregnancies?}

The mechanisms in which assisted reproduction technologies increases the risk for preterm birth are still under investigation. Aside the contribution of ART to the increase number of multiple gestations (especially twins) that increases the risk for preterm delivery; the mechanisms leading to preterm delivery in singleton gestation conceived by ART have not been thoroughly investigated yet. Preliminary evidence suggests that underlying maternal conditions that may lead to infertility including insulin resistance and inflammation may contribute to this observation.

\subsubsection{Preterm parturition as a syndrome}

The implicit paradigm that has governed much of the study of preterm parturition is that term and preterm labor are fundamentally the same process except for the gestational age at which they occur (Romero, Espinoza et al., 2004a; Romero, Espinoza et al., 2006b) and share a 'common pathway'. The common pathway of human parturition is defined as the anatomical, physiological, biochemical, endocrinological, immunological, and clinical events that occur in the mother and/or fetus in both term and preterm labor. The fundamental difference between term and preterm parturition is that the former results from physiological activation of the common pathway, while preterm labor arises from pathological processes that extemporaneously activate one or more of the components of the common pathway of parturition. 
Preterm labor (PTL) is the clinical presentation of different underlying mechanisms, (Romero, Espinoza et al., 2004c) including: intrauterine infection, (Romero, Sirtori et al., 1989; Romero, Mazor et al., 1988b; Minkoff, 1983; Goncalves, Chaiworapongsa et al., 2002) uteroplacental ischemia, (Romero, Sepulveda et al., 1993; Combs, Katz et al., 1993; Arias, 1990; Arias, Rodriquez et al., 1993) uterine over-distention, (Hill, Breckle et al., 1987; Phelan, Park et al., 1990; Besinger and Carlson, 1995) cervical disease, (Romero, Mazor et al., 1993; Romero, Espinoza et al., 2006a; Romero, 1996; Heath, Southall et al., 1998; Hassan, Romero et al., 2000) abnormal allograft reaction, (Romero, Sepulveda et al., 1993) allergic phenomena, (Holloway, Warner et al., 2000; Jones, Miles et al., 1996; Rudolph, Reinicke et al., 1993) and endocrine disorders. (Belt, Baldassare et al., 1999; Allport, Pieber et al., 2001) The current taxonomy of disease in obstetrics is based on the clinical presentation of the mother and not on the mechanism of disease responsible for the clinical manifestations. The term 'preterm labor' does not indicate whether the condition is caused by infection, a vascular insult, uterine overdistension, an abnormal allogeneic recognition, stress, or some other pathological process. The same applies to pre-eclampsia, intrauterine growth restriction, fetal death, recurrent abortions, as well as, nausea and vomiting during pregnancy, and failure to progress in labor, in which the diagnoses simply describe the clinical manifestations without consideration of the specific etiology. The lack of recognition that these conditions simply represent a collection of signs and symptoms with little reference to the underlying mechanisms of disease may be responsible for the expectation that one diagnostic test and treatment will detect and cure each of these conditions. This has implications for the fundamental understanding of the biology of preterm parturition and the clinical strategies to diagnose, treat, and prevent spontaneous preterm labour (Romero, Espinoza et al., 2004a; Romero, Espinoza et al., 2006b).

\subsubsection{Intrauterine Infection and/or inflammation}

Systemic and subclinical infections are a leading cause of preterm birth. Indeed, pyelonephritis and pneumonia are frequently associated with the onset of premature labor and delivery. (Benedetti, Valle et al., 1982; Cunningham, Morris et al., 1973; Fan, Pastorek et al., 1987; Finland and Dublin T.D., 1939; Gilles, Lawson et al., 1969; Herd and Jordan, 1981; Hibbard, Thrupp et al., 1967; Kass, 1962; Madinger, Greenspoon et al., 1989; McLane, 1939; Oxhorn, 1955; Stevenson, Glasko A.J. et al., 1951; Wing and Troppoli D.V., 1930) Similarly, subclinical intrauterine infection is a frequent and important mechanism of disease leading to premature contraction, preterm labor and preterm birth. (Minkoff, 1983; Romero, Mazor et al., 1988a; Bang, 1987; Fidel, Jr., Romero et al., 1994; Kullander, 1977; McDuffie, Jr., Sherman et al., 1992; McKay and Wong, 1963; Rieder and Thomas, 1960; Romero, Munoz et al., 1994; Skarnes and Harper, 1972; Takeda and Tsuchiya I., 1953; Zahl and Bjerknes, 1943; Gomez, Ghezzi et al., 1995; Romero, Sirtori et al., 1989; Goncalves, Chaiworapongsa et al., 2002) Microbiological and histo-pathological studies suggest that infection-related inflammation may account for 25 to $40 \%$ of cases of preterm deliveries.

Goncalves et al (Goncalves, Chaiworapongsa et al., 2002) studied the rate of positive amniotic fluid cultures for microorganisms in women with preterm labor and intact membranes. The authors reviewed the results of amniotic fluid cultures from 33 studies and the prevalence of microbial invasion of amniotic fluid among patients with preterm labor was 12.8\% (Goncalves, Chaiworapongsa et al., 2002; Romero, Espinoza et al., 2002), and about $50 \%$ of them were polymicrobial. The rate of microbial invasion of the amniotic cavity in patients with preterm labor and intact membrane is gestational age dependant. It is as 
high as $45 \%$ at $23-26$ weeks and decreases to $11.5 \%$ at $31-34$ weeks of gestation (Watts, Krohn et al., 1992). Thus, the earlier the gestational age at preterm birth, the more likely that microbial invasion of the amniotic cavity is present (Watts, Krohn et al., 1992). In preterm PROM, the prevalence of a positive amniotic fluid culture for microorganisms is approximately 32.4\%. (Goncalves, Chaiworapongsa et al., 2002; Romero, Espinoza et al., 2002) However, when amniocenteses were performed at the time of the onset of labor, $75 \%$ of patients had microbial invasion of the amniotic cavity (Romero, Quintero et al., 1988), suggesting that some patients are already infected prior to the clinical rupture of membranes, while others are infected after the membrane have ruptured. The rate of microbial invasion of amniotic cavity among women presenting with a cervical insufficiency in the mid-trimester is around 33\% (range 13\%-52\%) (Romero, Gonzalez et al., 1992; Bujold, Morency et al., 2008) and $45 \%$ to $51 \%$ in the early third trimester (Bujold, Morency et al., 2008). In addition, a recent study has demonstrated that while only $8 \%$ of patients with cervical insufficiency had a positive amniotic fluid culture, $80 \%$ have intra-amniotic inflammation determined by a positive rapid MMP-8 kit (Lee, Romero et al., 2008). Patients with intra-amniotic inflammation and negative amniotic fluid culture had a shorter amniocentesis-to-delivery interval and a lower gestational age at delivery than patients without intra-amniotic infection/inflammation. In twin gestations, microbial invasion of the amniotic cavity occurs in $11.9 \%$ of patients presenting with preterm labor and deliver preterm (Romero, Manogue et al., 1989; Romero, Mazor et al., 1988b). The most common microbial organisms isolated from the amniotic fluid of patients with preterm parturition were genital mycoplasmas, Fusobacterium species Streptococcus agalactiae, Petostreptococcus spp., Fusobacterium spp., Staphylococcus aureus, Gardenerella vaginalis, Streptococcus viridans, and Bacterioides spp. (Alanen, 1998; Hitti, Riley et al., 1997; Averbuch, Mazor et al., 1995; Carroll, Papaioannou et al., 1996; Cotton, Hill et al., 1984; Coultrip and Grossman, 1992; Garite, Freeman et al., 1979; Zlatnik, Cruikshank et al., 1984; Romero, Quintero et al., 1988; Romero, Gonzalez et al., 1992)

The association between infection and/or inflammation and preterm birth in ART pregnancies is implied from recently published data. A prospective cohort study that included 144,018 treatment cycles reported that tubal causes of infertility were associated with increased odds of preterm birth (Nelson and Lawlor, 2011). Kamiyama et al (Kamiyama, Teruya et al., 2004) reported that among women undergoing IVF-ET, those who had endotoxin concentrations $>200 \mathrm{pg} / \mathrm{mL}$ in menstrual effluent did not conceive, while $30 \%$ of those with lower endotoxin concentrations got pregnant. Thus, preexisting endometrial microbial invasion with Gram negative bacteria is associated with failure of IVF-ET, either because of failure of implantation or the induction of sub clinical spontaneous abortion (Romero, Espinoza et al., 2004b). Endotoxin is a component of the cell wall of Gram negative bacteria and its detection in biological fluid is evidence of microbial invasion of a sterile compartment such as the amniotic cavity. An increased concentration in non-sterile body fluids such as cervical mucus or vaginal fluid is an indication of enlarged Grannegative microbial population and has been reported in women with bacterial vaginosis (Romero, Espinoza et al., 2004b).

\subsubsection{Bacterial vaginosis and preterm birth}

Bacterial vaginosis is a risk factor for spontaneous preterm birth with intact or ruptures membranes (Leitich, Bodner-Adler et al., 2003). The rate of bacterial vaginosis during pregnancy is $15-20 \%$; however, $50 \%$ of these patients are asymptomatic. A meta-analysis 
(Leitich, Bodner-Adler et al., 2003) of 18 studies (20,232 patients) concluded that bacterial vaginosis was associated with an increased risk for preterm delivery < 37 weeks of gestation (OR 2.19, 95\%CI 1.54-3.12), and this effect was significant among singleton gestations, as well as among low and high risk pregnancies for preterm delivery. Detection of bacterial vaginosis $<16$ weeks of pregnancy was associated with an increased risk for preterm birth (OR 7.55, 95\%CI 1.8-31.65) (Leitich, Bodner-Adler et al., 2003). Bacterial vaginosis was also found to be associated with intra-amniotic infection, histologic chorioamnionitis, preterm PROM, first trimester losses in women who conceived after in vitro fertilization, and second trimesters abortions, as well as post cesarean section endometritis and wound infection (Vidaeff and Ramin, 2006; Newton, Piper et al., 1997; Ralph, Rutherford et al., 1999; LlahiCamp, Rai et al., 1996; Watts, Krohn et al., 1990; Watts, Eschenbach et al., 1989; Chaim, Mazor et al., 1997).

Patients who undergo IVF treatments have a rate of bacterial vaginosis of about $25 \%$ (Liversedge, Turner et al., 1999; Wilson, Ralph et al., 2002) which is higher than that observed in other groups of patients (11-15\%) (Eschenbach, Gravett et al., 1984; Pavletic, WolnerHanssen et al., 1999; Eschenbach, 1993; McGregor, Allen et al., 2001; McGregor and French, 2000; Sobel, 2000; Ugwumadu, 2002). Moreover, bacterial vaginosis was more common among infertile patients with tubal occlusion (Wilson, Ralph et al., 2002), which is independently associated with an increased risk for preterm birth (Nelson and Lawlor, 2011). Bacterial vaginosis was also more common in unovulatory women and those with unexplained infertility than in infertile couples due to male factor or endometriosis (Wilson, Ralph et al., 2002).

Randomized clinical trials for the prevention of preterm birth by antibiotic treatment of patients with bacterial vaginosis have yielded contradictory results (McDonald, O'Loughlin et al., 1997; Kekki, Kurki et al., 2001; Ugwumadu, Manyonda et al., 2003; Guaschino, Ricci et al., 2003; Okun, Gronau et al., 2005; Shennan, Crawshaw et al., 2006; McDonald, Brocklehurst et al., 2005; Carey, Klebanoff et al., 2000). The randomized placebo control trial of the NICHD MFMU network included 1953 women with bacterial vaginosis who were assigned to treatment with oral metronidazol or placebo (Carey, Klebanoff et al., 2000). Treatment with metronidazol was not associated with a significant reduction in the rate of preterm birth. Moreover, a sub-analysis of high risk patients for preterm delivery demonstrated a higher rate of preterm delivery and preterm PROM in the treatment group (Carey, Klebanoff et al., 2000). A Cochrane review concluded that, overall, antibiotic treatment of bacterial vaginosis did not reduce the risk for preterm birth; however, treatment before 20 weeks of gestation may reduce the risk for preterm delivery < 37 weeks (OR 0.72 95\% CI 0.55-0.95) (McDonald, Brocklehurst et al., 2007). In conclusion, treatment of bacterial vaginosis before 20 weeks of gestation in patients with a history of previous preterm birth, may reduce the risk for preterm PROM and low birthweight.

\subsubsection{Utero-placenta ischemia}

Abnormal placentation and vascular lesions in the fetal and maternal sides of the placenta are the second most prevalent lesions observed in patients who deliver preterm (Arias, Rodriquez et al., 1993). Several possible mechanisms can lead to such findings including vaginal and decidual bleeding, spontaneous or iatrogenic death of intrauterine sibling, and uterine vascular changes such as atherosclerosis that are more prevalent in older parturient. 
First trimester bleeding among patients with singleton gestation who conceived by ART was associated with an increased risk for: 1) recurrent second-trimester (OR 4.56, 95\% CI $=2.76$ 7.56) and third-trimester bleeding (OR 2.85, 95\% CI = 1.42- 5.73); 2) preterm PROM (OR 2.44, 95\% CI 1.38-4.31); 3) preterm contractions (OR 2.27, 95\% CI 1.48-3.47) as well as increased the risk for preterm birth (OR 1.64, 95\% CI $=1.05-2.55)$ and extreme preterm birth (OR 3.05, 95\% CI 1.12-8.31); and 4) NICU admissions (OR 1.75, 95\% CI 1.21-2.54) (De Sutter, Bontinck et al., 2006). The origin of vaginal bleeding associated with preterm birth can be either decidual or placental.

Vascular pathology is one of the mechanisms leading to decidual hemorrhage and subsequent preterm birth. Arias et al (Arias, Rodriquez et al., 1993) reported the rate of vascular lesions in placentae of patients with preterm labor was $34 \%$ and $35 \%$ of those with PROM, in comparison to only in $12 \%$ in those of women who delivered at term. The rate of failure of transformation of spiral arteries is higher among patients and preterm labor with intact membranes as well as those with preterm PROM than in patients who delivered at term (Kim, Bujold et al., 2003; Kim, Chaiworapongsa et al., 2002; Romero, Kusanovic et al., 2011; Lockwood, Krikun et al., 2007). Moreover, the changes in the uterine vasculature associated with maternal age contribute as well for the vascular pathology. Indeed, Crawford et al (Crawford, Davis et al., 1997) studied whether uterine artery atherosclerosis is associated with known cardiovascular risk factors in women undergoing hysterectomy. Among the 59 premenopausal women, 55.9\% had intimal thickening, $40.7 \%$ had simple plaques and $3.7 \%$ had complex lesions in the uterine artery samples. Among postmenopausal women, $40 \%$ had intimal fibrosis, $20 \%$ had simple plaques, and $40 \%$ had complex lesions. Postmenopausal status was correlated strongly with the presence of advanced atherosclerotic disease $(\mathrm{P}<0.001)$. Postmenopausal women had significantly greater intimal area $(P=0.01)$, intimal area/medial area $(P=0.002)$, intimal area/vessel area $(\mathrm{P}=0.002)$, maximal intimal thickness/medial thickness $(\mathrm{P}=0.01)$, and significantly less medial thickness $(\mathrm{P}<0.001)$. A significant linear correlation existed between age and the intimal/medial ratio among premenopausal women $(\mathrm{P}=0.04)$ and postmenopausal women $(\mathrm{P}$ $=0.01$ ). Patients with electrocardiogram (ECG) abnormalities had significantly greater intimal/medial area as well $(\mathrm{P}=0.02)$. Hypertension was associated with complex lesions among the postmenopausal patients $(P=0.01)$. Preoperative cholesterol levels greater than 200 $\mathrm{mg} / \mathrm{dL}$ were associated with greater intimal thickness $(\mathrm{P}=0.05)$ and intimal thickness/medial thickness $(P=0.03$ ) (Crawford, Davis et al., 1997). Moreover, Naeye et al (Naeye, 1983) reported that sclerotic lesions in the myometrial arteries are a possible cause of underperfusion because the proportion of arteries with these lesions increased from $11 \%$ at age 17 to 19 years to $83 \%$ after the age of 36 . This finding is in accord with the report that uterine artery PI during pregnancy increases with maternal age (Pirhonen, Bergersen et al., 2005). These observations are supported also by the clinical findings including an increased rate of SGA neonates among patients with preterm labor and intact membranes as well as those with preterm PROM, and the higher prevalence of low birthweight in ART pregnancies.

Decidual bleeding is thought to play a role in the pathogenesis of preterm labor and preterm PROM leading to preterm birth. Indeed, hemosiderin deposition, that are regarded as a marker for bleeding are found in the decidua and retro-chorionic hematoma formation is present in $37.5 \%$ of patients who deliver preterm after PROM between 22 and 32 weeks of gestation, and $36 \%$ of patients with preterm delivery and intact membranes (Salafia, LopezZeno et al., 1995). In contrast these lesions are found only in $0.8 \%$ of placentas of those who deliver at term. 
The effect of decidual bleeding on the activation of premature uterine contractions and/or rupture of membranes is thought to be mediated by thrombin (Lockwood, Krikun et al., 2007; Lockwood, Paidas et al., 2009). The decidua is reach with tissue factor the most potent activator of the coagulation cascade. Thus, any minor decidual bleeding activates the coagulation cascade leading to the generation of thrombin thrombin (Stephenson, Lockwood et al.,2005; Lockwood, Toti et al., 2005; Sarno, Schatz et al., 2006; Lockwood, Krikun et al., 2007). Evidence in support of the increase activation of the coagulation cascade among patients with preterm labor and intact membranes as well as women with preterm PROM include: 1) women with spontaneous preterm labor without intra-amniotic infection or inflammation and women with vaginal bleeding who delivered preterm, have a lower median maternal plasma protein $\mathrm{Z}$ (a co factor of protein $\mathrm{Z}$ dependent protease inhibitor that inhibits the activity of factor $X$ ) than that of normal pregnant women (Kusanovic, Espinoza et al., 2007); 2) regardless to the presence of intra-amniotic infection/inflammation, women with preterm labor and intact membranes have a higher median tissue factor activity and a lower median tissue factor pathway inhibitor than those with a normal pregnancy 3) patients with preterm PROM have a higher median maternal plasma tissue factor concentration and a lower median TFPI concentrations than normal pregnant women (Erez, Espinoza et al., 2008); 4) patients with PTL as well as those with preterm PROM have a higher median maternal plasma thrombin-antithrombin III concentration than that of women with a normal pregnancy (Chaiworapongsa, Espinoza et al., 2002; Elovitz, Baron et al., 2001; Rosen, Kuczynski et al., 2001); and 5) maternal plasma thrombin-antithrombin III complex concentration in the mid trimester were lower in patients about to deliver preterm than in those who subsequently delivered at term (Hackney, Catov et al., 2010).

Moreover, increased thrombin generation was detected not only in the maternal circulation but also in the amniotic fluid (Erez,Romero,et al.,2009). Women with preterm labor who delivered preterm had a higher median thrombin anti-thrombin III concentration than those who delivered at term (Erez, Romer et al., 2009). This was particularly evident among those without intra-amniotic infection/inflammation, in which elevated amniotic fluid of thrombin anti-thrombin complex concentrations were associated with a shorter amniocentesis to delivery interval and a lower gestational age at delivery than those with normal or low concentrations of this complex (Erez,Romero,et al.,2009). A vanishing twin can be an additional possible source for increase intrauterine thrombin generation that may lead to preterm birth. Indeed, vanishing twins among women who conceived by IVF/ICSI was associated with a higher rate of preterm birth $<37$ and $<32$ weeks of gestation, especially in the vanishing of the twin occur in later stages of gestation (Pinborg, Lidegaard et al., 2005). A possible explanation for this observation is the report that intrauterine fetal demise is associated with an increased intra-amniotic thrombin generation (Erez, Gotsch et al., 2009). This may be the case also in patients with a vanishing twin, meaning, the increased thrombin generation associated with the dissolving of the dead twin increases the risk for preterm delivery of the surviving fetus.

Thrombin can activate preterm parturition through several mechanisms: 1) it has a uterotonic activity, indeed, the administration of a whole blood into a non-pregnant uterus generated uterine contractions that were not evident when saline or heparinzed blood were introduced into the uterine cavity (Elovitz, Saunders et al., 2000; Elovitz, Baron et al., 2001); 2) thrombin and activated coagulation factor $X$ can induce pro inflammatory cytokines production (IL-6 and IL-1) that may leads to prostaglandins generation and premature myometrial activation and contractions (Lockwood, Toti et al., 2005); and 3) thrombin 
activates matrix degrading enzymes such as matrix metalloproteneinases (MMPs) 1, 3 and 9 that can degrade the chorioamniotic membranes leading to rupture of membranes (Rosen, Schatz et al., 2002; Stephenson, Lockwood et al., 2005).

\subsubsection{Uterine over-distention}

Women with a multiple pregnancy are at increased risk for spontaneous preterm labor and preterm birth. Intra-amniotic pressure remains relatively constant throughout gestation despite the growth of the fetus and placenta. This has been attributed to progressive myometrial relaxation due to the effects of progesterone and endogenous myometrial relaxants such as nitric oxide (Sladek, Westerhausen-Larson et al., 1999). Stretching can, however, induce increased myometrial contractility (Laudanski and Rocki, 1975), prostaglandin release (Kloeck and Jung, 1973), expression of gap junction protein or connexin-43 (Ou, Orsino et al., 1997), and increased oxytocin receptor in pregnant and nonpregnant myometrium (Ou, Chen et al., 1998). The stretch-induced contraction- associated protein gene expression during pregnancy is inhibited by progesterone (Ou, Orsino et al., 1997). The effect of stretch increases in late gestation and is maximal during labor as a consequence of the relative reduction in uterine growth compared with fetal growth and of the declining circulating and/or local concentrations of progesterone (Ticconi and Lye, 2002; Chow and Lye, 1994; Ou, Orsino et al., 1997).

Mechanical stress induces activation of integrin receptors (Tzima, del Pozo et al., 2001), stretch-activated calcium channels (Holm, Rich et al., 2000; Farrugia, Holm et al., 1999), phosphorylation of platelet-derived growth factor receptor (Hu, Bock et al., 1998) and activation of $\mathrm{G}$ proteins ( $\mathrm{Li}$ and $\mathrm{Xu}, 2000 ; \mathrm{Hu}$, Bock et al., 1998). Once mechanical force is sensed, it leads to activation of protein kinase $C$ and mitogen- activated protein kinases, increased gene expression of c-fos and c-jun, and enhanced binding activity of transcription factor activator protein-1 (Shynlova, Oldenhof et al., 2002; Oldenhof, Shynlova et al., 2002; Mitchell and Lye, 2002; Mitchell and Lye, 2001; Piersanti and Lye, 1995; Lefebvre, Piersanti et al., 1995). Other effects of physical forces relevant to myometrium include increased expression of prostaglandin $\mathrm{H}$ synthase 2 (Wu, Ma et al., 1999), superoxide dismutase, and nitric oxide synthase. The nature of force/pressure-sensing mechanisms of the myometrium has yet to be determined. A role for integrins and their ligands has been proposed for other organs (Shyy and Chien, 2002; Lee, Millward-Sadler et al., 2002). Stretch may not only induce increased myometrial contractility but may also modify the contractile response through 'mechanoelectrical feedback' similar to the one reported in the heart. The chorioamniotic membranes are distended by $40 \%$ at 25-29 weeks of gestation, $60 \%$ at 30-34 weeks of gestation, and $70 \%$ at term (Millar, Stollberg et al., 2000). Stretching of the membranes in vitro induces histological changes characterized by elongation of the amnion cells and increased production of collagenase activity and IL-8 (Maradny, Kanayama et al., 1996; Maehara, Kanayama et al., 1996), while stretching of amnion cells in culture results in increased production of prostaglandin E2 (Kanayama and Fukamizu, 1989). Recent studies using an in vitro cell culture model for fetal membrane distension revealed upregulation of IL-8 and pre-B-cell colony-enhancing factor (Nemeth, Tashima et al., 2000). When fetal membrane explants were distended in an in vitro distension device to mimic the situation in vivo, and the gene expressions of distended explants were compared with that of nondistended explants, three genes, namely IL enhancer binding factor 2, huntingtininteracting protein 2, and interferon-stimulated gene encoding a $54 \mathrm{kDa}$ protein, were found to be upregulated (Nemeth, Millar et al., 2000). Collectively, these observations suggest that 
mechanical forces associated with uterine overdistension may result in activation of mechanisms leading to membrane rupture.

\subsubsection{Insulin resistance}

The association between infertility and maternal insulin resistance is well documented and polycystic ovary disease is its classical feature (Lobo, 1995; Barbieri, 1992; Ruutiainen and Seppala, 1991; Franks, Robinson et al., 1996; Davison, 1998; Taylor, 1998; Sills, Perloe et al., 2000; Scarpitta and Sinagra, 2000; Gutmann and Corson, 2001; Nestler, Stovall et al., 2002; Moran and Norman, 2002; Ben-Shlomo, 2003). Indeed, these patients have a higher rate of infertility or sub fertility. The rate of pregnancy complications among patients with polycystic ovary disease is increased and women with PCOS demonstrated a significantly higher risk of developing gestational diabetes [odds ratio (OR) 2.94; 95\% CI: 1.70-5.08], gestational hypertension (OR 3.67; 95\% CI: 1.98-6.81), pre-eclampsia (OR 3.47; 95\% CI: 1.956.17) and preterm birth (OR 1.75; 95\% CI: 1.16-2.62). Their babies had a significantly higher risk of admission to a neonatal intensive care unit (OR 2.31; 95\% CI: 1.25-4.26) and a higher perinatal mortality (OR 3.07; 95\% CI: 1.03-9.21), unrelated to multiple births (Boomsma, Eijkemans et al., 2006). Thus these findings suggest that insulin resistance may contribute to preterm birth in twin gestations especially among patients with PCOS. The exact mechanisms leading to preterm birth due to maternal insulin resistance are not clear, recent reports suggest that alteration in adipocytokines may be involved in this process (MazakiTovi, Romero et al., 2008; Mazaki-Tovi, Romero et al., 2009a; Mazaki-Tovi, Romero et al., 2009b; Mazaki-Tovi, Romero et al., 2010; Mittal, Romero et al., 2009).

\subsubsection{Endocrine effect of ART}

The controlled ovarian hyperstimulation during ART cycles has endocrine implication that may contribute to the increasing rate of preterm birth in these patients. Human Chorionic Gonadotropin (hCG) induces the secretion of relaxin by the corpus luteum (Kristiansson, Svardsudd et al., 1996; Weiss, Goldsmith et al., 1993). Due to the ovarian hyperstimulation during ART cycle the maternal luteal mass is more prominent than that observed during spontaneously conceived pregnancies resulting in the significant increase in relaxin secretion in response to hCG, and indeed, pregnancies following ART were associated with hyper relaxinemia (Kristiansson, Svardsudd et al., 1996; Weiss, Goldsmith et al., 1993). Higher maternal relaxin concentrations were found to be significantly associated with preterm birth (Iams, Goldsmith et al., 2001; Vogel, Salvig et al., 2001; Vogel, GlavindKristensen et al., 2002). Relaxin acts by promoting collagenolysis through inducing the activity of matrixmetaloproteinase (MMP) 1-3 and inhibiting tissue inhibitor of metalloprotease-1 (TIMP-1) (Palejwala, Stein et al., 2001); the net effect is remodeling and ripening of the uterine cervix and increased uterotonic activity. Progesterone can counter act relaxin activity by inducing an anti-inflammatory response and decrease the MMP concentrations and uterine contractility (Palejwala, Stein et al., 2001).

\section{Prevention of preterm birth}

The prevention of preterm birth is one of the major objectives of modern obstetrics. In the US there is an initiative to reduce the rate of preterm birth to $6.1 \%$ by 2010 , and the March of Dimes has made this topic its main field of interest. In spite of all efforts, at present there is 
no specific treatment for spontaneous preterm birth and this is attributed to the syndromic nature of preterm delivery that cannot be resolved by a single medication or intervention. Currently there is wide agreement regarding the beneficial effect of two treatments: (1) the administration of corticosteroids for patients at risk for preterm birth to reduced acute neonatal morbidity; and (2) prophylactic antibiotic treatment for patients with preterm PROM that has occurred from 24 to 32 weeks of gestation (Mercer, Miodovnik et al., 1997; Kenyon, Taylor et al., 2001) but not for preterm labor with intact membranes (Kenyon, Brocklehurst et al., 2008). This treatment has been proven to prolong pregnancy and reduce the rate of acute neonatal morbidity in patients with preterm PROM (Kenyon, Brocklehurst et al., 2008). However, the results of the follow up of children after 7 years were as follows: (1) In children who were born after preterm PROM, neither antibiotic regime was associated with a significant effect on the overall level of behavioral, medical status and academics achievements (Kenyon, Pike et al., 2008). (2) In contrast, prophylactic antibiotic treatment of patients with preterm labor had a negative effect on the children's outcome at the age of 7. Treatment with erythromycin was associated with increased functional impairment of children of mother with preterm labor and intact membranes (Kenyon, Pike et al., 2008). The more worrisome outcome was the higher rate of cerebral palsy among children whose mothers were treated with erythromycin (OR 1.93, 95\% CI 1.21-3.09) as well as in those treated with co-amoxicalve (OR 1.69, 95\% CI 1.07-2.67) (Kenyon, Pike et al., 2008). Thus, prophylactic antibiotic treatment should not be administrated to patients and preterm labor with intact membranes.

Yet, these treatments are targeted to reduce the rate of complications rather than to prevent the "disease". In the recent years, attempts to prevent spontaneous preterm birth are mainly by two approaches: (1) the administration of progesterone to patients with a history of preterm birth or with a short sonographic cervix; and (2) placement of a cerclage for cervical os insufficiency.

\subsection{Progesterone for the prevention of preterm birth}

Progestogens administration for the prevention of recurrent abortion or preterm birth has been a subject of investigation (Papiernik-Berkhauer, 1970; LEVINE, 1964; BISHOP, RICHARDS et al., 1950; BISHOP and RICHARDS, 1952; Check, Chase et al., 1987; Tognoni, Ferrario et al., 1980; Gerhard, Gwinner et al., 1987; Johnson, Austin et al., 1975; Hauth, Gilstrap, III et al., 1983; Yemini, Borenstein et al., 1985; Hartikainen-Sorri, Kauppila et al., 1980; Breart, Lanfranchi et al., 1979) and meta-analyses (Daya, 1989; Goldstein, Berrier et al., 1989; Keirse, 1990) or several decades. However, progesterone gained a wide acceptance as a valid treatment for the prevention of preterm birth (2003) only after the publication of the studies by da Fonseca (da Fonseca, Bittar et al., 2003) and the NICHD MFMU (Meis, Klebanoff et al., 2003) who investigated its efficacy in the prevention of preterm birth in women with a history of preterm delivery.

Da Fonseca et al. (da Fonseca, Bittar et al., 2003) reported the results of a randomized, double-blinded, placebo-controlled study including 142 high-risk singleton pregnancies including patients with: (1) at least one previous spontaneous preterm birth; (2) prophylactic cervical cerclage; or (3) a uterine malformation. The patients were randomized to receive either daily vaginal suppository of micronized progesterone $(100 \mathrm{mg})$ or placebo, from 24 to 34 weeks of gestation. The rate of preterm delivery $<37$ weeks and $<34$ weeks was lower in the progesterone group than in the placebo group ( $<37$ weeks, progesterone: $13.8 \%$ vs. 
placebo: $28.5 \%, p=0.03$; and < 34 weeks, progesterone: $2.8 \%$ vs. $18.6 \%, p=0.002$ ) (da Fonseca, Bittar et al., 2003). The authors concluded that prophylactic vaginal progesterone appeared to reduce the rate of preterm delivery in women at high risk for preterm birth (da Fonseca, Bittar et al., 2003).

The NICHD-MFMU network (Meis, Klebanoff et al., 2003) reported the results of a multicenter double-blind, placebo-controlled clinical trial testing whether 17-hydroxy progesterone caproate (OHPC) administration can reduce the rate of preterm delivery in patients with a history of spontaneous preterm birth. The patients were enrolled at 16 to 20 weeks of gestation and randomly assigned in a 2:1 ratio to receive either a weekly injection of $250 \mathrm{mg}$ of 17-OHPC or a weekly injection of placebo until delivery or 36 weeks of gestation. Treatment with 17-OHPC significantly reduced the rate of preterm delivery at less than 37 weeks, less than 35 weeks, and less than 32 weeks of gestation ( $<37$ weeks, RR $0.66 ; 95 \%$ CI 0.54-0.81; <35 weeks, RR 0.67; 95\% CI 0.48-0.93; and <32 weeks, RR 0.58; 95\% CI 0.37-0.91]. Moreover, neonates born to women treated with 17-OHPC had significantly lower rates of NEC, IVH and need for supplemental oxygen (Meis, Klebanoff et al., 2003). Thus, among women at high risk for preterm delivery, a weekly injection of 17-OHPC resulted in a reduction in the rate of recurrent preterm birth and several neonatal complications (Meis, Klebanoff et al., 2003). The beneficial effect of 17-OHPC and vaginal progesterone in the reduction of preterm birth and of 17-OHPC in the reduction of the rate of neonates with low birth weight were further supported by systematic reviews meta-analyses and a Cochrane review (Sanchez-Ramos, Kaunitz et al., 2005; Dodd, Crowther et al., 2005; Coomarasamy, Thangaratinam et al., 2006; Mackenzie, Walker et al., 2006; Dodd, Flenady et al., 2006).

In 2007, three new randomized clinical trials on the efficacy of progestogens in preventing preterm birth were reported (Rouse, Caritis et al., 2007; O'Brien, Adair et al., 2007; Fonseca, Celik et al., 2007). The recent randomized clinical trials yielded conflicting results. O'Brien et al (O'Brien, Adair et al., 2007) reported the results of a multinational, randomized, doubleblind, placebo-controlled trial of progesterone vaginal gel administration to patients with a history of spontaneous preterm birth between 20 to 35 weeks of gestation. Women were randomized, between 18 to 22 completed weeks of gestation, to receive daily treatment of progesterone vaginal polycarbophil-based gel (Crinone ${ }^{\circledR}, 8 \%, 90 \mathrm{mg}$ ) or placebo (Replens ${ }^{\circledR}$ ) that were self-administered either until delivery, 37 weeks of gestation, or the occurrence of PROM. Vaginal progesterone did not reduce the rate of preterm birth at $\leq 32, \leq 35$, or $\leq 37$ weeks of gestation. Moreover, there were no differences in the neonatal and maternal outcomes (O'Brien, Adair et al., 2007).

The beneficial effect of progesterone in patients with a sonographic short cervix has been recently reported (Facchinetti, Paganelli et al., 2007). A randomized prospective clinical trial (Facchinetti, Paganelli et al., 2007) in which women with preterm labor and intact membranes (25 to $336 / 7$ weeks) were allocated to either observation or IM administration of $341 \mathrm{mg}$ of 17-OHPC twice a week until 36 weeks of gestation or delivery was performed. Patients allocated to receive 17-OHPC had a longer sonographic cervical length than those in the observation group (Facchinetti, Paganelli et al., 2007); suggesting that progesterone may have major effects on the uterine cervix.

Fonseca et al. (Fonseca, Celik et al., 2007) reported the results of a randomized clinical trial evaluating the efficacy of vaginal progesterone in reducing the rate of preterm birth in women with a sonographic short cervix ( $\leq 15 \mathrm{~mm}$ by transvaginal ultrasound between 20 to 25 weeks of gestation). Women were allocated to daily vaginal administration of $200 \mathrm{mg}$ of micronized progesterone or placebo (safflower oil) from 24 to 34 weeks. The frequency of 
spontaneous preterm delivery $<34$ weeks was significantly lower in the progesterone group than that in patients allocated to placebo $(19.2 \%$ vs. $34.4 \%$; $p=0.007)$ (Fonseca, Celik et al., 2007). A secondary analysis of this trial indicated that among women without a history of delivery $<34$ weeks, the incidence of preterm birth was significantly lower in women receiving progesterone than in those allocated to placebo (RR 0.57, 95\% CI 0.35-0.93) suggesting that progesterone may be beneficial to patients with a sonographic short cervix even without a history of preterm birth (Fonseca, Celik et al., 2007).

The secondary retrospective analysis (Defranco, O'Brien et al., 2007) of the study by O'Brien et al (O'Brien, Adair et al., 2007). supports the findings of Fonseca et al (Fonseca, Celik et al., 2007) that patients with a short cervix may benefit from vaginal progesterone administration. However, the authors (Defranco, O'Brien et al., 2007) reported that vaginal progesterone gel may have a beneficial effect in reducing preterm delivery $<32$ weeks of gestation at a sonographic cervical length of $<28 \mathrm{~mm}$ (Defranco, O'Brien et al., 2007). These findings imply that the cutoff of $15 \mathrm{~mm}$ may be too stringent and progesterone may also work in women with a longer cervix. As the frequency of a cervix of $\leq 15 \mathrm{~mm}$ is $1.7 \%$ but that of $<28 \mathrm{~mm}$ is about $10 \%$ (Iams, Goldenberg et al., 1996; Iams, Goldenberg et al., 2001; Iams, Johnson et al., 1995), this could expand the therapeutic range of progesterone.

The study of De Franco et al (Defranco, O'Brien et al., 2007) provides the first hint that vaginal progesterone administration may improve infant outcome in properly selected patients. The frequency of NICU admission was lower in women with a cervical length of $\leq 30 \mathrm{~mm}$ and $<28 \mathrm{~mm}$ and who had received progesterone treatment than in those allocated to placebo. The same was the case for the duration of NICU length of stay (Defranco, O'Brien et al., 2007). However, these conclusions must be considered tentative because they derive from a secondary analysis which is intended to be hypothesis-generating.

In contrast to the results in singleton gestations, the administration of progesterone for the prevention of preterm birth in twin gestation had no beneficial effect. Hartikainen-Sorri et al (Hartikainen-Sorri, Kauppila et al., 1980) more than twenty-five years ago, and recently Rouse et al (Rouse, Caritis et al., 2007) reported the results of a multicenter, placebocontrolled, double-blind, randomized clinical trials of 17-OHPC for prevention of preterm birth in twin pregnancies. Both studies concluded that there was no beneficial effect of 17$\mathrm{OHPC}$ administration for the prevention of preterm birth in twin gestation.

\subsection{The role of cervical cerclage in the prevention of preterm birth}

Keeping with the view that cervical insufficiency is a mechanical disorder of the cervix, placement of a cervical stitch (cerclage) has been proposed as a treatment for this disorder. The clinical value of cervical cerclage has been subject of many observational and randomized clinical trials (To, Palaniappan et al., 2002; 1993; Althuisius, Dekker et al., 2002; Althuisius, Dekker et al., 2000; Althuisius, Dekker et al., 2001; Althuisius, Dekker et al., 2003; Lazar, Gueguen et al., 1984; To, Alfirevic et al., 2004) and systematic reviews (Belej-Rak, Okun et al., 2003; Drakeley, Roberts et al., 2003a; Drakeley, Roberts et al., 2003b). Yet controversies still exist regarding the subset of patients who will benefit from cerclage.

The current evidence suggests the following: (1) Women who are at low risk for preterm delivery (by history) and have a sonographic short cervix $(\leq 15 \mathrm{~mm})$ will not benefit from cerclage (To, Alfirevic et al., 2004). (2) The benefit of cerclage in women who have a high risk for preterm birth, both by history and a sonographic short cervix observed during the current pregnancy, is controversial (Berghella, Odibo et al., 2004; Rust, Atlas et al., 2000; 
Rust, Atlas et al., 2001; Althuisius, Dekker et al., 2000; Althuisius, Dekker et al., 2001). However, a recent randomize clinical trial conducted by the NICHD MFM network among patients with a prior preterm birth $<34$ weeks of gestation. Patients with a cervical length $<25 \mathrm{~mm}$ randomly assigned to cerclage reported a beneficial effect of cerclage (Owen, Hankins et al., 2009). This benefit was highly concentrated in women with very short cervical length (<15 mm) (Owen, Hankins et al., 2009). (3) Among patients at risk for preterm delivery, serial sonographic examinations of the cervix followed by cerclage in those who shortened the cervix is a reasonable alternative to prophylactic placement of cerclage based upon uncontrolled studies (Guzman, Forster et al., 1998; To, Alfirevic et al., 2004; Higgins, Kornman et al., 2004). (4) The role of prophylactic cerclage in high-risk patients without a sonographic short cervix for the prevention of preterm delivery/midtrimester abortion (by history) is unclear (1993; Althuisius, Dekker et al., 2001; Lazar, Gueguen et al., 1984; Odibo, Elkousy et al., 2003; Rush, Isaacs et al., 1984). (5) In one trial, emergency cerclage combined with indomethacin administration appeared to reduce the rate of preterm delivery in patients with the clinical presentation of "cervical insufficiency" (Althuisius, Dekker et al., 2003). This evidence indicates that only patients with the clinical presentation of "acute cervical insufficiency" and those with a previous history consistent with "cervical insufficiency" or spontaneous preterm birth and a progressive shortening of the cervix demonstrated by ultrasound may benefit from cerclage placement (Althuisius, Dekker et al., 2001; Althuisius, Dekker et al., 2003; Berghella, Rafael et al., 2011; Berghella, Keeler et al., 2010; Owen, Hankins et al., 2009). The inflammatory status of the endocervix may be an additional criterion to identify those patients that could benefit from cerclage placement and those for whom this intervention may be harmful. (Sakai, Shiozaki et al., 2006)

\subsection{The role of progesterone in primary prevention of preterm birth}

A recent study by Hassan et al (Hassan, Romero et al., 2011)raised for the first time the possibility of primary prevention of preterm delivery. The study included patients with a short cervix (cervical length between 10-20 mm) who were randomized at 19-24 weeks to the administration of daily vaginal progesterone gel vs. placebo, regardless to their obstetrical history. 32,091 were screened, of them 733 had a short cervix, and 465 were randomized. Women at the progesterone group had a significant reduction in the rate of preterm birth before 33 weeks of gestation and a significant lower rate of neonatal complications in comparison to those in the placebo group (Hassan, Romero et al., 2011). Thus, cervical length is an effective risk assessment tool for the identification of patients at risk for preterm birth and vaginal progesterone gel can prevent preterm delivery in a significant portion of patients with a short cervix.

\section{Summary}

Assisted reproduction aids a substantial proportion of women to conceive and deliver, however, these pregnancies are at increased risk for preterm birth. Some of the mechanisms leading to preterm parturition in these patients are inherited from the nature of conception like multiple gestations along with their complications. In addition, especially among singleton gestations, ART are an independent risk factor for preterm delivery and this may result from the underlying mechanisms leading to maternal infertility like infection/inflammation of the genital tract as well as other mechanisms. Thus, women who conceived following ART cycles should be followed and treated as a patient at risk for preterm birth. 


\section{References}

[1] (1993) Final report of the Medical Research Council/Royal College of Obstetricians and Gynaecologists multicentre randomised trial of cervical cerclage. MRC/RCOG Working Party on Cervical Cerclage. Br J Obstet Gynaecol, 100, 516-523.

[2] (1999) Preterm singleton births--United States, 1989-1996. MMWR Morb Mortal Wkly Rep, 48, 185-189.

[3] (1994b) Abstracts of the 10th annual meeting of the European Society of Human Reproduction and Embryology. Brussels, Belgium, 27-29 June 1994. Hum Reprod, 9 Suppl 4:1-227., 1-227.

[4] (2003) ACOG Committee Opinion. Use of progesterone to reduce preterm birth. Obstet Gynecol, 102, 1115-1116.

[5] (1994a) Abstracts of the 10th annual meeting of the European Society of Human Reproduction and Embryology. Brussels, Belgium, 27-29 June 1994. Hum Reprod, 9 Suppl 4:1-227., 1-227.

[6] (2008) Centers for Disease Control and Prevention, American Society for Reproductive Medicine, Society for Assisted Reproductive Technology. 2006 Assisted Reproductive Technology Success Rates: National summary and fertility clinic reports. In Centers for Disease Control and Prevention, pp. 1-584.

[7] Baxi A and Kaushal M (2008) Outcome of twin pregnancies conceived after assisted reproductive techniques. J Hum Reprod Sci, 1, 25-28.

[8] Alanen A (1998) Polymerase chain reaction in the detection of microbes in amniotic fluid. Ann Med, 30, 288-295.

[9] Allen EG, Freeman SB, Druschel C, Hobbs CA, O'Leary LA, Romitti PA, Royle MH, Torfs CP, and Sherman SL (2009) Maternal age and risk for trisomy 21 assessed by the origin of chromosome nondisjunction: a report from the Atlanta and National Down Syndrome Projects. Hum Genet, 125, 41-52.

[10] Allen VM, Wilson RD, and Cheung A (2006) Pregnancy outcomes after assisted reproductive technology. J Obstet Gynaecol Can, 28, 220-250.

[11] Allport VC, Pieber D, Slater DM, Newton R, White JO, and Bennett PR (2001) Human labour is associated with nuclear factor-kappaB activity which mediates cyclooxygenase- 2 expression and is involved with the 'functional progesterone withdrawal'. Mol Hum Reprod, 7, 581-586.

[12] Althuisius S, Dekker G, Hummel P, Bekedam D, Kuik D, and van GH (2002) Cervical Incompetence Prevention Randomized Cerclage Trial (CIPRACT): effect of therapeutic cerclage with bed rest vs. bed rest only on cervical length. Ultrasound Obstet Gynecol, 20, 163-167.

[13] Althuisius SM, Dekker GA, Hummel P, Bekedam DJ, and van Geijn HP (2001) Final results of the Cervical Incompetence Prevention Randomized Cerclage Trial (CIPRACT): therapeutic cerclage with bed rest versus bed rest alone. Am J Obstet Gynecol, 185, 1106-1112.

[14] Althuisius SM, Dekker GA, Hummel P, and van Geijn HP (2003) Cervical incompetence prevention randomized cerclage trial: emergency cerclage with bed rest versus bed rest alone. Am J Obstet Gynecol, 189, 907-910.

[15] Althuisius SM, Dekker GA, van Geijn HP, Bekedam DJ, and Hummel P (2000) Cervical incompetence prevention randomized cerclage trial (CIPRACT): study design and preliminary results. Am J Obstet Gynecol, 183, 823-829. 
[16] Ananth CV, Getahun D, Peltier MR, Salihu HM, and Vintzileos AM (2006) Recurrence of spontaneous versus medically indicated preterm birth. Am J Obstet Gynecol, 195, 643-650.

[17] Ananth CV, Joseph KS, Oyelese Y, Demissie K, and Vintzileos AM (2005) Trends in preterm birth and perinatal mortality among singletons: United States, 1989 through 2000. Obstet Gynecol, 105, 1084-1091.

[18] Ananth CV and Vintzileos AM (2006a) Epidemiology of preterm birth and its clinical subtypes. J Matern Fetal Neonatal Med, 19, 773-782.

[19] Ananth CV and Vintzileos AM (2006b) Maternal-fetal conditions necessitating a medical intervention resulting in preterm birth. Am J Obstet Gynecol, 195, 15571563.

[20] Arias F (1990) Placental insufficiency: an important cause of preterm labor and preterm premature ruptured membranes. Presented at the 10th Annual Meeting of the Society of Perinatal Obstetricians, 23-27 January 1990, Houston, TX, USA.

[21] Arias F, Rodriquez L, Rayne SC, and Kraus FT (1993) Maternal placental vasculopathy and infection: two distinct subgroups among patients with preterm labor and preterm ruptured membranes. Am J Obstet Gynecol, 168, 585-591.

[22] Atkinson AB and Marlier E (2010) Income and living conditions in Europe., European Union, 2010.

[23] Averbuch B, Mazor M, Shoham-Vardi I, Chaim W, Vardi H, Horowitz S, and Shuster M (1995) Intra-uterine infection in women with preterm premature rupture of membranes: maternal and neonatal characteristics. Eur J Obstet Gynecol Reprod Biol, 62, 25-29.

[24] Bang B (1987) The etiology of epizootic abortion. J Comp Anthol Ther, 10, 125.

[25] Barbieri RL (1992) Hyperandrogenism: new insights into etiology, diagnosis, and therapy. Curr Opin Obstet Gynecol, 4, 372-379.

[26] Barker DJ (2004) The developmental origins of adult disease. J Am Coll Nutr, 23, 588S595S.

[27] Belej-Rak T, Okun N, Windrim R, Ross S, and Hannah ME (2003) Effectiveness of cervical cerclage for a sonographically shortened cervix: a systematic review and meta-analysis. Am J Obstet Gynecol, 189, 1679-1687.

[28] Belt AR, Baldassare JJ, Molnar M, Romero R, and Hertelendy F (1999) The nuclear transcription factor NF-kappaB mediates interleukin-1beta-induced expression of cyclooxygenase-2 in human myometrial cells. Am J Obstet Gynecol, 181, 359-366.

[29] Ben-Shlomo I (2003) The polycystic ovary syndrome: what does insulin resistance have to do with it? Reprod Biomed Online, 6, 36-42.

[30] Benedetti TJ, Valle R, and Ledger WJ (1982) Antepartum pneumonia in pregnancy. Am J Obstet Gynecol, 144, 413-417.

[31] Berghella V, Keeler SM, To MS, Althuisius SM, and Rust OA (2010) Effectiveness of cerclage according to severity of cervical length shortening: a meta-analysis. Ultrasound Obstet Gynecol, 35, 468-473.

[32] Berghella V, Odibo AO, and Tolosa JE (2004) Cerclage for prevention of preterm birth in women with a short cervix found on transvaginal ultrasound examination: a randomized trial. Am J Obstet Gynecol, 191, 1311-1317. 
[33] Berghella V, Rafael TJ, Szychowski JM, Rust OA, and Owen J (2011) Cerclage for short cervix on ultrasonography in women with singleton gestations and previous preterm birth: a meta-analysis. Obstet Gynecol, 117, 663-671.

[34] Berkowitz GS, Skovron ML, Lapinski RH, and Berkowitz RL (1990) Delayed childbearing and the outcome of pregnancy. N Engl J Med, 322, 659-664.

[35] Besinger R and Carlson N (1995) The physiology of preterm labor. In Keith L, Papiernik E, Keith D, and Luke B (eds) Multiple Pregnancy: Epidemiology, Gestation and Perinatal Outcome. Parthenon Publishing, London, p. 415.

[36] BISHOP PM and RICHARDS NA (1952) Habitual abortion; further observations on the prophylactic value of progesterone pellet implantation. Br Med J, 1, 244-246.

[37] BISHOP PM, RICHARDS NA, and DOLL R (1950) Habitual abortion; prophylactic value of progesterone pellet implantation. Br Med J, 2, 130-133.

[38] Blickstein I, Jones C, and Keith LG (2003) Zygotic-splitting rates after single-embryo transfers in in vitro fertilization. N Engl J Med, 348, 2366-2367.

[39] Blickstein I, Verhoeven HC, and Keith LG (1999) Zygotic splitting after assisted reproduction. N Engl J Med, 340, 738-739.

[40] Boomsma CM, Eijkemans MJ, Hughes EG, Visser GH, Fauser BC, and Macklon NS (2006) A meta-analysis of pregnancy outcomes in women with polycystic ovary syndrome. Hum Reprod Update, 12, 673-683.

[41] Boulet SL, Schieve LA, Nannini A, Ferre C, Devine O, Cohen B, Zhang Z, Wright V, and Macaluso M (2008) Perinatal outcomes of twin births conceived using assisted reproduction technology: a population-based study. Hum Reprod, 23, 1941-1948.

[42] Breart G, Lanfranchi M, Chavigny C, Rumeau-Rouquette C, and Sureau C (1979) A comparative study of the efficiency of hydroxyprogesterone caproate and of chlormadinone acetate in the prevention of premature labor. Int J Gynaecol Obstet, 16, 381-384.

[43] Bujold E, Morency AM, Rallu F, Ferland S, Tetu A, Duperron L, Audibert F, and Laferriere C (2008) Bacteriology of amniotic fluid in women with suspected cervical insufficiency. J Obstet Gynaecol Can, 30, 882-887.

[44] Carey JC, Klebanoff MA, Hauth JC, Hillier SL, Thom EA, Ernest JM, Heine RP, Nugent $\mathrm{RP}$, Fischer ML, Leveno KJ et al (2000) Metronidazole to prevent preterm delivery in pregnant women with asymptomatic bacterial vaginosis. National Institute of Child Health and Human Development Network of Maternal-Fetal Medicine Units. N Engl J Med, 342, 534-540.

[45] Carolan M, Davey MA, Biro MA, and Kealy M (2011) Older maternal age and intervention in labor: a population-based study comparing older and younger firsttime mothers in Victoria, Australia. Birth, 38, 24-29.

[46] Carroll SG, Papaioannou S, Ntumazah IL, Philpott-Howard J, and Nicolaides KH (1996) Lower genital tract swabs in the prediction of intrauterine infection in preterm prelabour rupture of the membranes. Br J Obstet Gynaecol, 103, 54-59.

[47] Chaim W, Mazor M, and Leiberman JR (1997) The relationship between bacterial vaginosis and preterm birth. A review. Arch Gynecol Obstet, 259, 51-58.

[48] Chaiworapongsa T, Espinoza J, Yoshimatsu J, Kim YM, Bujold E, Edwin S, Yoon BH, and Romero R (2002) Activation of coagulation system in preterm labor and preterm premature rupture of membranes. J Matern Fetal Neonatal Med, 11, 368373. 
[49] Chan OT, Mannino FL, and Benirschke K (2007) A retrospective analysis of placentas from twin pregnancies derived from assisted reproductive technology. Twin Res Hum Genet, 10, 385-393.

[50] Check JH, Chase JS, Nowroozi K, Wu CH, and Adelson HG (1987) Progesterone therapy to decrease first-trimester spontaneous abortions in previous aborters. Int $\mathrm{J}$ Fertil, 32, 192-193.

[51] Chen XK, Wen SW, Bottomley J, Smith GN, Leader A, and Walker MC (2009) In vitro fertilization is associated with an increased risk for preeclampsia. Hypertens Pregnancy, 28, 1-12.

[52] Chow L and Lye SJ (1994) Expression of the gap junction protein connexin-43 is increased in the human myometrium toward term and with the onset of labor. Am J Obstet Gynecol, 170, 788-795.

[53] Cleary-Goldman J, Malone FD, Vidaver J, Ball RH, Nyberg DA, Comstock CH, Saade GR, Eddleman KA, Klugman S, Dugoff L et al (2005) Impact of maternal age on obstetric outcome. Obstet Gynecol, 105, 983-990.

[54] Combs CA, Katz MA, Kitzmiller JL, and Brescia RJ (1993) Experimental preeclampsia produced by chronic constriction of the lower aorta: validation with longitudinal blood pressure measurements in conscious rhesus monkeys. Am J Obstet Gynecol, $169,215-223$.

[55] Coomarasamy A, Thangaratinam S, Gee H, and Khan KS (2006) Progesterone for the prevention of preterm birth: a critical evaluation of evidence. Eur J Obstet Gynecol Reprod Biol, 129, 111-118.

[56] Cotton DB, Hill LM, Strassner HT, Platt LD, and Ledger WJ (1984) Use of amniocentesis in preterm gestation with ruptured membranes. Obstet Gynecol, 63, 38-43.

[57] Coultrip LL and Grossman JH (1992) Evaluation of rapid diagnostic tests in the detection of microbial invasion of the amniotic cavity. Am J Obstet Gynecol, 167, 1231-1242.

[58] Crawford BS, Davis J, and Harrigill K (1997) Uterine artery atherosclerotic disease: histologic features and clinical correlation. Obstet Gynecol, 90, 210-215.

[59] Cunningham FG, Morris GB, and Mickal A (1973) Acute pyelonephritis of pregnancy: A clinical review. Obstet Gynecol, 42, 112-117.

[60] da Fonseca EB, Bittar RE, Carvalho MH, and Zugaib M (2003) Prophylactic administration of progesterone by vaginal suppository to reduce the incidence of spontaneous preterm birth in women at increased risk: a randomized placebocontrolled double-blind study. Am J Obstet Gynecol, 188, 419-424.

[61] Daniel Y, Ochshorn Y, Fait G, Geva E, Bar-Am A, and Lessing JB (2000) Analysis of 104 twin pregnancies conceived with assisted reproductive technologies and 193 spontaneously conceived twin pregnancies. Fertil Steril, 74, 683-689.

[62] Das UG and Sysyn GD (2004) Abnormal fetal growth: intrauterine growth retardation, small for gestational age, large for gestational age. Pediatr Clin North Am, 51, 63954, viii.

[63] Davison RM (1998) New approaches to insulin resistance in polycystic ovarian syndrome. Curr Opin Obstet Gynecol, 10, 193-198.

[64] Daya S (1989) Efficacy of progesterone support for pregnancy in women with recurrent miscarriage. A meta-analysis of controlled trials. Br J Obstet Gynaecol, 96, 275-280. 
[65] De Sutter P, Bontinck J, Schutysers V, Van der EJ, Gerris J, and Dhont M (2006) Firsttrimester bleeding and pregnancy outcome in singletons after assisted reproduction. Hum Reprod, 21, 1907-1911.

[66] Defranco EA, O'Brien JM, Adair CD, Lewis DF, Hall DR, Fusey S, Soma-Pillay P, Porter $\mathrm{K}$, How H, Schakis R et al (2007) Vaginal progesterone is associated with a decrease in risk for early preterm birth and improved neonatal outcome in women with a short cervix: a secondary analysis from a randomized, double-blind, placebocontrolled trial. Ultrasound Obstet Gynecol, 30, 697-705.

[67] Dodd JM, Crowther CA, Cincotta R, Flenady V, and Robinson JS (2005) Progesterone supplementation for preventing preterm birth: a systematic review and metaanalysis. Acta Obstet Gynecol Scand, 84, 526-533.

[68] Dodd JM, Flenady V, Cincotta R, and Crowther CA (2006) Prenatal administration of progesterone for preventing preterm birth. Cochrane Database Syst Rev, CD004947.

[69] Drakeley AJ, Roberts D, and Alfirevic Z (2003b) Cervical stitch (cerclage) for preventing pregnancy loss in women. Cochrane Database Syst Rev, CD003253.

[70] Drakeley AJ, Roberts D, and Alfirevic Z (2003a) Cervical cerclage for prevention of preterm delivery: meta-analysis of randomized trials. Obstet Gynecol, 102, 621-627.

[71] Elovitz MA, Baron J, and Phillippe M (2001) The role of thrombin in preterm parturition. Am J Obstet Gynecol, 185, 1059-1063.

[72] Elovitz MA, Saunders T, scher-Landsberg J, and Phillippe M (2000) Effects of thrombin on myometrial contractions in vitro and in vivo. Am J Obstet Gynecol, 183, 799-804.

[73] Erez O, Espinoza J, Chaiworapongsa T, Gotsch F, Kusanovic JP, Than NG, Mazaki-Tovi S, Vaisbuch E, Papp Z, Yoon BH et al (2008) A link between a hemostatic disorder and preterm PROM: a role for tissue factor and tissue factor pathway inhibitor. J Matern Fetal Neonatal Med, 21, 732-744.

[74] Erez O, Gotsch F, Mazaki-Tovi S, Vaisbuch E, Kusanovic JP, Kim CJ, Chaiworapongsa T, Hoppensteadt D, Fareed J, Than NG et al (2009) Evidence of maternal platelet activation, excessive thrombin generation, and high amniotic fluid tissue factor immunoreactivity and functional activity in patients with fetal death. J Matern Fetal Neonatal Med, 22, 672-687.

[75] Erez O, Mayer A, Shoham-Vardi I, Dukler D, and Mazor M (2008) Primiparity, assisted reproduction, and preterm birth in twin pregnancies: a population based study. Arch Gynecol Obstet, 277, 311-317.

[76] Erez O, Romer R, Vaisbuch E, Chaiworapongsa T, Kusanovic JP, Mazaki-Tovi S, Gotsch F, Gomez R, Maymon E, Pacora P et al (2009) Changes in amniotic fluid concentration of thrombin-antithrombin III complexes in patients with preterm labor: evidence of an increased thrombin generation. J Matern Fetal Neonatal Med, 22, 971-982.

[77] Erez O, Vardi IS, Hallak M, Hershkovitz R, Dukler D, and Mazor M (2006) Preeclampsia in twin gestations: association with IVF treatments, parity and maternal age. J Matern Fetal Neonatal Med, 19, 141-146.

[78] Eschenbach DA (1993) Bacterial vaginosis and anaerobes in obstetric-gynecologic infection. Clin Infect Dis, 16 Suppl 4:S282-7., S282-S287.

[79] Eschenbach DA, Gravett MG, Chen KC, Hoyme UB, and Holmes KK (1984) Bacterial vaginosis during pregnancy. An association with prematurity and postpartum complications. Scand J Urol Nephrol Suppl, 86:213-22., 213-222. 
[80] Facchinetti F, Paganelli S, Comitini G, Dante G, and Volpe A (2007) Cervical length changes during preterm cervical ripening: effects of 17-alpha-hydroxyprogesterone caproate. Am J Obstet Gynecol, 196, 453-454.

[81] Fan YD, Pastorek JG, Miller JM, Jr., and Mulvey J (1987) Acute pyelonephritis in pregnancy. Am J Perinatol, 4, 324-326.

[82] Farrugia G, Holm AN, Rich A, Sarr MG, Szurszewski JH, and Rae JL (1999) A mechanosensitive calcium channel in human intestinal smooth muscle cells. Gastroenterology, 117, 900-905.

[83] Fidel PL, Jr., Romero R, Wolf N, Cutright J, Ramirez M, Araneda H, and Cotton DB (1994) Systemic and local cytokine profiles in endotoxin-induced preterm parturition in mice. Am J Obstet Gynecol, 170, 1467-1475.

[84] Finland $M$ and Dublin T.D. (1939) Pneumococcic pneumonia complicating pregnancy and the puerperium. JAMA, 112, 1027-1032.

[85] Fonseca EB, Celik E, Parra M, Singh M, and Nicolaides KH (2007) Progesterone and the risk of preterm birth among women with a short cervix. N Engl J Med, 357, 462-469.

[86] Franks S, Robinson S, and Willis DS (1996) Nutrition, insulin and polycystic ovary syndrome. Rev Reprod, 1, 47-53.

[87] Fretts RC, Schmittdiel J, McLean FH, Usher RH, and Goldman MB (1995) Increased maternal age and the risk of fetal death. N Engl J Med, 333, 953-957.

[88] Garite TJ, Freeman RK, Linzey EM, and Braly P (1979) The use of amniocentesis in patients with premature rupture of membranes. Obstet Gynecol, 54, 226-230.

[89] Gerhard I, Gwinner B, Eggert-Kruse W, and Runnebaum B (1987) Double-blind controlled trial of progesterone substitution in threatened abortion. Biol Res Pregnancy Perinatol, 8, 26-34.

[90] Gilbert WM, Nesbitt TS, and Danielsen B (1999) Childbearing beyond age 40: pregnancy outcome in 24,032 cases. Obstet Gynecol, 93, 9-14.

[91] Gilles HM, Lawson JB, Sibelas M, Voller A, and Allan N (1969) Malaria, anaemia and pregnancy. Ann Trop Med Parasitol, 63, 245-263.

[92] Goldenberg RL, Culhane JF, Iams JD, and Romero R (2008) Epidemiology and causes of preterm birth. Lancet, 371, 75-84.

[93] Goldstein P, Berrier J, Rosen S, Sacks HS, and Chalmers TC (1989) A meta-analysis of randomized control trials of progestational agents in pregnancy. Br J Obstet Gynaecol, 96, 265-274.

[94] Gomez R, Ghezzi F, Romero R, Munoz H, Tolosa JE, and Rojas I (1995) Premature labor and intra-amniotic infection. Clinical aspects and role of the cytokines in diagnosis and pathophysiology. Clin Perinatol, 22, 281-342.

[95] Goncalves LF, Chaiworapongsa T, and Romero R (2002a) Intrauterine infection and prematurity. Ment Retard Dev Disabil Res Rev, 8, 3-13.

[96] Guaschino S, Ricci E, Franchi M, Frate GD, Tibaldi C, Santo DD, Ghezzi F, Benedetto C, Seta FD, and Parazzini F (2003) Treatment of asymptomatic bacterial vaginosis to prevent pre-term delivery: a randomised trial. Eur J Obstet Gynecol Reprod Biol, 110, 149-152.

[97] Gunby J, Bissonnette F, Librach C, and Cowan L (2011) Assisted reproductive technologies (ART) in Canada: 2007 results from the Canadian ART Register. Fertil Steril, 95, 542-547. 
[98] Gurunath S, Pandian Z, Anderson RA, and Bhattacharya S (2011) Defining infertility--a systematic review of prevalence studies. Hum Reprod Update.

[99] Gutmann JN and Corson SL (2001) Female reproductive endocrinology at the turn of the millennium. Int J Fertil Womens Med, 46, 101-115.

[100] Guzman ER, Forster JK, Vintzileos AM, Ananth CV, Walters C, and Gipson K (1998) Pregnancy outcomes in women treated with elective versus ultrasound-indicated cervical cerclage. Ultrasound Obstet Gynecol, 12, 323-327.

[101] Hackney DN, Catov JM, and Simhan HN (2010) Low concentrations of thrombininhibitor complexes and the risk of preterm delivery. Am J Obstet Gynecol, 203, 184-186.

[102] Hansen M, Colvin L, Petterson B, Kurinczuk JJ, de KN, and Bower C (2009) Twins born following assisted reproductive technology: perinatal outcome and admission to hospital. Hum Reprod, 24, 2321-2331.

[103] Hartikainen-Sorri AL, Kauppila A, and Tuimala R (1980) Inefficacy of 17 alphahydroxyprogesterone caproate in the prevention of prematurity in twin pregnancy. Obstet Gynecol, 56, 692-695.

[104] Hassan SS, Romero R, Berry SM, Dang K, Blackwell SC, Treadwell MC, and Wolfe HM (2000) Patients with an ultrasonographic cervical length $<$ or $=15 \mathrm{~mm}$ have nearly a $50 \%$ risk of early spontaneous preterm delivery. Am J Obstet Gynecol, 182, 14581467.

[105] Hassan SS, Romero R, Vidyadhari D, Fusey S, Baxter JK, Khandelwal M, Vijayaraghavan J, Trivedi Y, Soma-Pillay P, Sambarey P et al (2011) Vaginal progesterone reduces the rate of preterm birth in women with a sonographic short cervix: a multicenter, randomized, double-blind, placebo-controlled trial. Ultrasound Obstet Gynecol, 38, 18-31.

[106] Hauth JC, Gilstrap LC, III, Brekken AL, and Hauth JM (1983) The effect of 17 alphahydroxyprogesterone caproate on pregnancy outcome in an active-duty military population. Am J Obstet Gynecol, 146, 187-190.

[107] Heath VC, Southall TR, Souka AP, Elisseou A, and Nicolaides KH (1998) Cervical length at 23 weeks of gestation: prediction of spontaneous preterm delivery. Ultrasound Obstet Gynecol, 12, 312-317.

[108] Herd $\mathrm{N}$ and Jordan $\mathrm{T}(1981)$ An investigtion of malaria during pregnancy in Zimbabwe. Afr J Med, 27, 62.

[109] Hibbard L, Thrupp L, Summeril S, Smale M, and Adams R (1967) Treatment of pyelonephritis in pregnancy. Am J Obstet Gynecol, 98, 609-615.

[110] Higgins SP, Kornman LH, Bell RJ, and Brennecke SP (2004) Cervical surveillance as an alternative to elective cervical cerclage for pregnancy management of suspected cervical incompetence. Aust N Z J Obstet Gynaecol, 44, 228-232.

[111] Hill LM, Breckle R, Thomas ML, and Fries JK (1987) Polyhydramnios: ultrasonically detected prevalence and neonatal outcome. Obstet Gynecol, 69, 21-25.

[112] Hitti J, Riley DE, Krohn MA, Hillier SL, Agnew KJ, Krieger JN, and Eschenbach DA (1997) Broad-spectrum bacterial rDNA polymerase chain reaction assay for detecting amniotic fluid infection among women in premature labor. Clin Infect Dis, 24, 1228-1232. 
[113] Holloway JA, Warner JO, Vance GH, Diaper ND, Warner JA, and Jones CA (2000) Detection of house-dust-mite allergen in amniotic fluid and umbilical-cord blood. Lancet, 356, 1900-1902.

[114] Holm AN, Rich A, Sarr MG, and Farrugia G (2000) Whole cell current and membrane potential regulation by a human smooth muscle mechanosensitive calcium channel. Am J Physiol Gastrointest Liver Physiol, 279, G1155-G1161.

[115] Hook EB, Cross PK, and Schreinemachers DM (1983) Chromosomal abnormality rates at amniocentesis and in live-born infants. JAMA, 249, 2034-2038.

[116] Hu Y, Bock G, Wick G, and Xu Q (1998) Activation of PDGF receptor alpha in vascular smooth muscle cells by mechanical stress. FASEB J, 12, 1135-1142.

[117] Iams JD, Goldenberg RL, Meis PJ, Mercer BM, Moawad A, Das A, Thom E, McNellis D, Copper RL, Johnson F et al (1996) The length of the cervix and the risk of spontaneous premature delivery. National Institute of Child Health and Human Development Maternal Fetal Medicine Unit Network. N Engl J Med, 334, 567-572.

[118] Iams JD, Goldenberg RL, Mercer BM, Moawad AH, Meis PJ, Das AF, Caritis SN, Miodovnik M, Menard MK, Thurnau GR et al (2001) The preterm prediction study: can low-risk women destined for spontaneous preterm birth be identified? Am J Obstet Gynecol, 184, 652-655.

[119] Iams JD, Goldsmith LT, and Weiss G (2001) The preterm prediction study: maternal serum relaxin, sonographic cervical length, and spontaneous preterm birth in twins. J Soc Gynecol Investig, 8, 39-42.

[120] Iams JD, Johnson FF, Sonek J, Sachs L, Gebauer C, and Samuels P (1995) Cervical competence as a continuum: a study of ultrasonographic cervical length and obstetric performance. Am J Obstet Gynecol, 172, 1097-1103.

[121] Institute of Medicine (US) Committee on Understanding Premature Birth and Assuring Healthy Outcomes; Behrman RE, Butler AS, editors. Preterm Birth: Causes, Consequences, and Prevention. Washington (DC): National Academies Press (US); 2007.

[122] Jackson RA, Gibson KA, Wu YW, and Croughan MS (2004) Perinatal outcomes in singletons following in vitro fertilization: a meta-analysis. Obstet Gynecol, 103, 551563.

[123] Jacobsson B, Ladfors L, and Milsom I (2004a) Advanced maternal age and adverse perinatal outcome. Obstet Gynecol, 104, 727-733.

[124] Johnson JW, Austin KL, Jones GS, Davis GH, and King TM (1975) Efficacy of 17alphahydroxyprogesterone caproate in the prevention of premature labor. N Engl J Med, 293, 675-680.

[125] Jones AC, Miles EA, Warner JO, Colwell BM, Bryant TN, and Warner JA (1996) Fetal peripheral blood mononuclear cell proliferative responses to mitogenic and allergenic stimuli during gestation. Pediatr Allergy Immunol, 7, 109-116.

[126] Joseph KS, Kramer MS, Marcoux S, Ohlsson A, Wen SW, Allen A, and Platt R (1998) Determinants of preterm birth rates in Canada from 1981 through 1983 and from 1992 through 1994. N Engl J Med, 339, 1434-1439.

[127] Kamiyama S, Teruya Y, Nohara M, and Kanazawa K (2004) Impact of detection of bacterial endotoxin in menstrual effluent on the pregnancy rate in in vitro fertilization and embryo transfer. Fertil Steril, 82, 788-792. 
[128] Kanayama N and Fukamizu H (1989) Mechanical stretching increases prostaglandin E2 in cultured human amnion cells. Gynecol Obstet Invest, 28, 123-126.

[129] Kass E (1962) Maternal urinary tract infection. NY State J Med, 1, 2822-2826.

[130] Keirse MJ (1990) Progestogen administration in pregnancy may prevent preterm delivery. Br J Obstet Gynaecol, 97, 149-154.

[131] Kekki M, Kurki T, Pelkonen J, Kurkinen-Raty M, Cacciatore B, and Paavonen J (2001) Vaginal clindamycin in preventing preterm birth and peripartal infections in asymptomatic women with bacterial vaginosis: a randomized, controlled trial. Obstet Gynecol, 97, 643-648.

[132] Kenyon S, Brocklehurst P, Jones D, Marlow N, Salt A, and Taylor D (2008) MRC ORACLE Children Study. Long term outcomes following prescription of antibiotics to pregnant women with either spontaneous preterm labour or preterm rupture of the membranes. BMC Pregnancy Childbirth, 8:14., 14.

[133] Kenyon S, Pike K, Jones DR, Brocklehurst P, Marlow N, Salt A, and Taylor DJ (2008) Childhood outcomes after prescription of antibiotics to pregnant women with spontaneous preterm labour: 7-year follow-up of the ORACLE II trial. Lancet, 372, 1319-1327.

[134] Kenyon SL, Taylor DJ, and Tarnow-Mordi W (2001) Broad-spectrum antibiotics for preterm, prelabour rupture of fetal membranes: the ORACLE I randomised trial. ORACLE Collaborative Group. Lancet, 357, 979-988.

[135] Kim YM, Bujold E, Chaiworapongsa T, Gomez R, Yoon BH, Thaler HT, Rotmensch S, and Romero R (2003) Failure of physiologic transformation of the spiral arteries in patients with preterm labor and intact membranes. Am J Obstet Gynecol, 189, 10631069.

[136] Kim YM, Chaiworapongsa T, Gomez R, Bujold E, Yoon BH, Rotmensch S, Thaler HT, and Romero R (2002) Failure of physiologic transformation of the spiral arteries in the placental bed in preterm premature rupture of membranes. Am J Obstet Gynecol, 187, 1137-1142.

[137] Kloeck FK and Jung H (1973) In vitro release of prostaglandins from the human myometrium under the influence of stretching. Am J Obstet Gynecol, 115, 10661069.

[138] Kristiansson P, Svardsudd K, von SB, and Wramsby H (1996) Supraphysiological serum relaxin concentration during pregnancy achieved by in-vitro fertilization is strongly correlated to the number of growing follicles in the treatment cycle. Hum Reprod, 11, 2036-2040.

[139] Kroon B, Harrison K, Martin N, Wong B, and Yazdani A (2011) Miscarriage karyotype and its relationship with maternal body mass index, age, and mode of conception. Fertil Steril, 95, 1827-1829.

[140] Kullander S (1977) Fever and parturition. An experimental study in rabbits. Acta Obstet Gynecol Scand Suppl, 77-85.

[141] Kusanovic JP, Espinoza J, Romero R, Hoppensteadt D, Nien JK, Kim CJ, Erez O, Soto E, Fareed J, Edwin S et al (2007) Plasma protein Z concentrations in pregnant women with idiopathic intrauterine bleeding and in women with spontaneous preterm labor. J Matern Fetal Neonatal Med, 20, 453-463.

[142] Lampinen R, Vehvilainen-Julkunen K, and Kankkunen P (2009) A review of pregnancy in women over 35 years of age. Open Nurs J, 3:33-8., 33-38. 
[143] Laudanski T and Rocki W (1975) The effects on stretching and prostaglandin F2alpha on the contractile and bioelectric activity of the uterus in rat. Acta Physiol Pol, 26, 385-393.

[144] Lazar P, Gueguen S, Dreyfus J, Renaud R, Pontonnier G, and Papiernik E (1984) Multicentred controlled trial of cervical cerclage in women at moderate risk of preterm delivery. Br J Obstet Gynaecol, 91, 731-735.

[145] Lee HS, Millward-Sadler SJ, Wright MO, Nuki G, Al-Jamal R, and Salter DM (2002) Activation of Integrin-RACK1/PKCalpha signalling in human articular chondrocyte mechanotransduction. Osteoarthritis Cartilage, 10, 890-897.

[146] Lee SE, Romero R, Park CW, Jun JK, and Yoon BH (2008) The frequency and significance of intraamniotic inflammation in patients with cervical insufficiency. Am J Obstet Gynecol, 198, 633-638.

[147] Lefebvre DL, Piersanti M, Bai XH, Chen ZQ, and Lye SJ (1995) Myometrial transcriptional regulation of the gap junction gene, connexin-43. Reprod Fertil Dev, 7, 603-611.

[148] Leitich H, Bodner-Adler B, Brunbauer M, Kaider A, Egarter C, and Husslein P (2003) Bacterial vaginosis as a risk factor for preterm delivery: a meta-analysis. Am J Obstet Gynecol, 189, 139-147.

[149] LEVINE L (1964) HABITUAL ABORTION. A CONTROLLED STUDY OF PROGESTATIONAL THERAPY. West J Surg Obstet Gynecol, 72:30-6., 30-36.

[150] Li C and Xu Q (2000) Mechanical stress-initiated signal transductions in vascular smooth muscle cells. Cell Signal, 12, 435-445.

[151] Liversedge NH, Turner A, Horner PJ, Keay SD, Jenkins JM, and Hull MG (1999) The influence of bacterial vaginosis on in-vitro fertilization and embryo implantation during assisted reproduction treatment. Hum Reprod, 14, 2411-2415.

[152] Llahi-Camp JM, Rai R, Ison C, Regan L, and Taylor-Robinson D (1996) Association of bacterial vaginosis with a history of second trimester miscarriage. Hum Reprod, 11, 1575-1578.

[153] Lobo RA (1995) Polycystic ovary syndrome/hyperandrogenic chronic anovulation. Adv Endocrinol Metab, 6:167-91., 167-191.

[154] Lockwood CJ, Krikun G, Rahman M, Caze R, Buchwalder L, and Schatz F (2007a) The role of decidualization in regulating endometrial hemostasis during the menstrual cycle, gestation, and in pathological states. Semin Thromb Hemost, 33, 111-117.

[155] Lockwood CJ, Paidas M, Murk WK, Kayisli UA, Gopinath A, Huang SJ, Krikun G, and Schatz F (2009) Involvement of human decidual cell-expressed tissue factor in uterine hemostasis and abruption. Thromb Res, 124, 516-520.

[156] Lockwood CJ, Toti P, Arcuri F, Paidas M, Buchwalder L, Krikun G, and Schatz F (2005) Mechanisms of abruption-induced premature rupture of the fetal membranes: thrombin-enhanced interleukin-8 expression in term decidua. Am J Pathol, 167, 1443-1449.

[157] Mackenzie R, Walker M, Armson A, and Hannah ME (2006) Progesterone for the prevention of preterm birth among women at increased risk: a systematic review and meta-analysis of randomized controlled trials. Am J Obstet Gynecol, 194, 12341242. 
[158] Madinger NE, Greenspoon JS, and Ellrodt AG (1989) Pneumonia during pregnancy: has modern technology improved maternal and fetal outcome? Am J Obstet Gynecol, 161, 657-662.

[159] Maehara K, Kanayama N, Maradny EE, Uezato T, Fujita M, and Terao T (1996) Mechanical stretching induces interleukin- 8 gene expression in fetal membranes: a possible role for the initiation of human parturition. Eur J Obstet Gynecol Reprod Biol, 70, 191-196.

[160] Maheshwari A, Porter M, Shetty A, and Bhattacharya S (2008) Women's awareness and perceptions of delay in childbearing. Fertil Steril, 90, 1036-1042.

[161] Maradny EE, Kanayama N, Halim A, Maehara K, and Terao T (1996) Stretching of fetal membranes increases the concentration of interleukin-8 and collagenase activity. Am J Obstet Gynecol, 174, 843-849.

[162] Martin JA, Hamilton BE, Sutton PD, Ventura SJ, Menacker F, Kirmeyer S, and Munson ML (2007) Births: Final Data for 2005. Natl Vital Stat Rep, 56, 1-104.

[163] Martin JA, Hamilton BE, Sutton PD, Ventura SJ, Mathews TJ, and Osterman MJ (2010) Births: Final Data for 2008. Natl Vital Stat Rep, 59, 1-72.

[164] Martin JA, Hamilton BE, Sutton PD, Ventura SJ, Menacker F, Kirmeyer S, and Mathews TJ (2009) Births: Final Data for 2006. Natl Vital Stat Rep, 57, 1-121.

[165] Mathews TJ and Hamilton BE (2002) Mean age of mother, 1970-2000. Natl Vital Stat Rep, 51, 1-13.

[166] Mazaki-Tovi S, Romero R, Kusanovic JP, Erez O, Gotsch F, Mittal P, Than NG, NhanChang CL, Hamill N, Vaisbuch E et al (2008) Visfatin/Pre-B cell colony-enhancing factor in amniotic fluid in normal pregnancy, spontaneous labor at term, preterm labor and prelabor rupture of membranes: an association with subclinical intrauterine infection in preterm parturition. J Perinat Med, 36, 485-496.

[167] Mazaki-Tovi S, Romero R, Kusanovic JP, Erez O, Pineles BL, Gotsch F, Mittal P, Gabor TN, Espinoza J, and Hassan SS (2007) Recurrent preterm birth. Semin Perinatol, 31, 142-158.

[168] Mazaki-Tovi S, Romero R, Vaisbuch E, Erez O, Chaiworapongsa T, Mittal P, Kim SK, Pacora P, Gotsch F, Dong Z et al (2009a) Maternal plasma visfatin in preterm labor. J Matern Fetal Neonatal Med, 22, 693-704.

[169] Mazaki-Tovi S, Romero R, Vaisbuch E, Erez O, Mittal P, Chaiworapongsa T, Kim SK, Pacora P, Yeo L, Gotsch F et al (2009b) Dysregulation of maternal serum adiponectin in preterm labor. J Matern Fetal Neonatal Med, 22, 887-904.

[170] Mazaki-Tovi S, Romero R, Vaisbuch E, Kusanovic JP, Erez O, Mittal P, Gotsch F, Chaiworapongsa T, Than NG, Kim SK et al (2010) Adiponectin in amniotic fluid in normal pregnancy, spontaneous labor at term, and preterm labor: a novel association with intra-amniotic infection/inflammation. J Matern Fetal Neonatal Med, 23, 120-130.

[171] McDonald H, Brocklehurst P, and Parsons J (2005b) Antibiotics for treating bacterial vaginosis in pregnancy. Cochrane Database Syst Rev, CD000262.

[172] McDonald HM, Brocklehurst P, and Gordon A (2007) Antibiotics for treating bacterial vaginosis in pregnancy. Cochrane Database Syst Rev, CD000262.

[173] McDonald HM, O'Loughlin JA, Vigneswaran R, Jolley PT, Harvey JA, Bof A, and McDonald PJ (1997) Impact of metronidazole therapy on preterm birth in women with bacterial vaginosis flora (Gardnerella vaginalis): a randomised, placebo controlled trial. Br J Obstet Gynaecol, 104, 1391-1397. 
[174] McDonald SD, Han Z, Mulla S, Ohlsson A, Beyene J, and Murphy KE (2010) Preterm birth and low birth weight among in vitro fertilization twins: a systematic review and meta-analyses. Eur J Obstet Gynecol Reprod Biol, 148, 105-113.

[175] McDuffie RS, Jr., Sherman MP, and Gibbs RS (1992) Amniotic fluid tumor necrosis factor-alpha and interleukin-1 in a rabbit model of bacterially induced preterm pregnancy loss. Am J Obstet Gynecol, 167, 1583-1588.

[176] McElrath TF, Hecht JL, Dammann O, Boggess K, Onderdonk A, Markenson G, Harper M, Delpapa E, Allred EN, and Leviton A (2008) Pregnancy disorders that lead to delivery before the 28th week of gestation: an epidemiologic approach to classification. Am J Epidemiol, 168, 980-989.

[177] McGovern PG, Llorens AJ, Skurnick JH, Weiss G, and Goldsmith LT (2004) Increased risk of preterm birth in singleton pregnancies resulting from in vitro fertilizationembryo transfer or gamete intrafallopian transfer: a meta-analysis. Fertil Steril, 82, 1514-1520.

[178] McGregor JA, Allen KG, Harris MA, Reece M, Wheeler M, French JI, and Morrison J (2001) The omega-3 story: nutritional prevention of preterm birth and other adverse pregnancy outcomes. Obstet Gynecol Surv, 56, S1-13.

[179] McGregor JA and French JI (2000) Bacterial vaginosis in pregnancy. Obstet Gynecol Surv, 55, S1-19.

[180] McKay DG and Wong TC (1963) The effect of bacterial endotoxin on the placenta of the rat. Am J Pathol, 42, 357-377.

[181] McLane CM (1939) Pyelitis of pregnancy: a five-year study. Am J Obstet Gynecol, 38, 117.

[182] Meis PJ, Goldenberg RL, Mercer BM, Iams JD, Moawad AH, Miodovnik M, Menard MK, Caritis SN, Thurnau GR, Bottoms SF et al (1998) The preterm prediction study: risk factors for indicated preterm births. Maternal-Fetal Medicine Units Network of the National Institute of Child Health and Human Development. Am J Obstet Gynecol, 178, 562-567.

[183] Meis PJ, Klebanoff M, Thom E, Dombrowski MP, Sibai B, Moawad AH, Spong CY, Hauth JC, Miodovnik M, Varner MW et al (2003) Prevention of recurrent preterm delivery by 17 alpha-hydroxyprogesterone caproate. N Engl J Med, 348, 2379-2385.

[184] Meis PJ, Michielutte R, Peters TJ, Wells HB, Sands RE, Coles EC, and Johns KA (1995) Factors associated with preterm birth in Cardiff, Wales. II. Indicated and spontaneous preterm birth. Am J Obstet Gynecol, 173, 597-602.

[185] Meis P, Ernest J, Moore M, Michielutte R, Sharp P, and Buescher PA (1987) Regional program for prevention of premature birth in northwestern North Carolina. American Journal of Obstetrics \& Gynecology, 157, 550-556.

[186] Menken J, Trussell J, and Larsen U (1986) Age and infertility. Science, 233, 1389-1394.

[187] Mercer BM, Miodovnik M, Thurnau GR, Goldenberg RL, Das AF, Ramsey RD, Rabello YA, Meis PJ, Moawad AH, Iams JD et al (1997) Antibiotic therapy for reduction of infant morbidity after preterm premature rupture of the membranes. A randomized controlled trial. National Institute of Child Health and Human Development Maternal-Fetal Medicine Units Network. JAMA, 278, 989-995.

[188] Millar LK, Stollberg J, DeBuque L, and Bryant-Greenwood G (2000) Fetal membrane distention: determination of the intrauterine surface area and distention of the fetal membranes preterm and at term. Am J Obstet Gynecol, 182, 128-134. 
[189] Minkoff H (1983) Prematurity: infection as an etiologic factor. Obstet Gynecol, 62, 137144.

[190] Mitchell JA and Lye SJ (2002) Differential expression of activator protein-1 transcription factors in pregnant rat myometrium. Biol Reprod, 67, 240-246.

[191] Mitchell JA and Lye SJ (2001) Regulation of connexin43 expression by c-fos and c-jun in myometrial cells. Cell Commun Adhes, 8, 299-302.

[192] Mittal P, Romero R, Mazaki-Tovi S, Tromp G, Tarca AL, Kim YM, Chaiworapongsa T, Kusanovic JP, Erez O, Than NG et al (2009) Fetal membranes as an interface between inflammation and metabolism: increased aquaporin 9 expression in the presence of spontaneous labor at term and chorioamnionitis. J Matern Fetal Neonatal Med, 22, 1167-1175.

[193] Moran LJ and Norman RJ (2002) The obese patient with infertility: a practical approach to diagnosis and treatment. Nutr Clin Care, 5, 290-297.

[194] Morcel K, Lavoue V, Beuchee A, Le LD, Poulain P, and Pladys P (2010) Perinatal morbidity and mortality in twin pregnancies with dichorionic placentas following assisted reproductive techniques or ovarian induction alone: a comparative study. Eur J Obstet Gynecol Reprod Biol, 153, 138-142.

[195] Moster D, Lie RT, and Markestad T (2008) Long-term medical and social consequences of preterm birth. N Engl J Med, 359, 262-273.

[196] Naeye RL (1983) Maternal age, obstetric complications, and the outcome of pregnancy. Obstet Gynecol, 61, 210-216.

[197] Nardi O, Zureik M, Courbon D, Ducimetiere P, and Clavel-Chapelon F (2006) Preterm delivery of a first child and subsequent mothers' risk of ischaemic heart disease: a nested case-control study. Eur J Cardiovasc Prev Rehabil, 13, 281-283.

[198] Nelson SM and Lawlor DA (2011) Predicting live birth, preterm delivery, and low birth weight in infants born from in vitro fertilisation: a prospective study of 144,018 treatment cycles. PLoS Med, 8, e1000386.

[199] Nemeth E, Millar LK, and Bryant-Greenwood G (2000) Fetal membrane distention: II. Differentially expressed genes regulated by acute distention in vitro. Am J Obstet Gynecol, 182, 60-67.

[200] Nemeth E, Tashima LS, Yu Z, and Bryant-Greenwood GD (2000) Fetal membrane distention: I. Differentially expressed genes regulated by acute distention in amniotic epithelial (WISH) cells. Am J Obstet Gynecol, 182, 50-59.

[201] Nepomnyaschy L and Reichman NE (2006) Low birthweight and asthma among young urban children. Am J Public Health, 96, 1604-1610.

[202] Nestler JE, Stovall D, Akhter N, Iuorno MJ, and Jakubowicz DJ (2002) Strategies for the use of insulin-sensitizing drugs to treat infertility in women with polycystic ovary syndrome. Fertil Steril, 77, 209-215.

[203] Newton ER, Piper J, and Peairs W (1997) Bacterial vaginosis and intraamniotic infection. Am J Obstet Gynecol, 176, 672-677.

[204] Nybo Andersen AM, Wohlfahrt J, Christens P, Olsen J, and Melbye M (2000) Maternal age and fetal loss: population based register linkage study. BMJ, 320, 1708-1712.

[205] O'Brien JM, Adair CD, Lewis DF, Hall DR, Defranco EA, Fusey S, Soma-Pillay P, Porter K, How H, Schackis R et al (2007) Progesterone vaginal gel for the reduction of recurrent preterm birth: primary results from a randomized, double-blind, placebocontrolled trial. Ultrasound Obstet Gynecol, 30, 687-696. 
[206] Odibo AO, Elkousy M, Ural SH, and Macones GA (2003) Prevention of preterm birth by cervical cerclage compared with expectant management: a systematic review. Obstet Gynecol Surv, 58, 130-136.

[207] Okun N, Gronau KA, and Hannah ME (2005) Antibiotics for bacterial vaginosis or Trichomonas vaginalis in pregnancy: a systematic review. Obstet Gynecol, 105, 857868.

[208] Oldenhof AD, Shynlova OP, Liu M, Langille BL, and Lye SJ (2002) Mitogen-activated protein kinases mediate stretch-induced c-fos mRNA expression in myometrial smooth muscle cells. Am J Physiol Cell Physiol, 283, C1530-C1539.

[209] Ou CW, Chen ZQ, Qi S, and Lye SJ (1998) Increased expression of the rat myometrial oxytocin receptor messenger ribonucleic acid during labor requires both mechanical and hormonal signals. Biol Reprod, 59, 1055-1061.

[210] Ou CW, Orsino A, and Lye SJ (1997) Expression of connexin-43 and connexin-26 in the rat myometrium during pregnancy and labor is differentially regulated by mechanical and hormonal signals. Endocrinology, 138, 5398-5407.

[211] Owen J, Hankins G, Iams JD, Berghella V, Sheffield JS, Perez-Delboy A, Egerman RS, Wing DA, Tomlinson M, Silver R et al (2009) Multicenter randomized trial of cerclage for preterm birth prevention in high-risk women with shortened midtrimester cervical length. Am J Obstet Gynecol, 201, 375-378.

[212] Oxhorn H (1955) The changing aspects of pneumonia complicating pregnancy. Am J Obstet Gynecol, 70, 1057.

[213] Palejwala S, Stein DE, Weiss G, Monia BP, Tortoriello D, and Goldsmith LT (2001) Relaxin positively regulates matrix metalloproteinase expression in human lower uterine segment fibroblasts using a tyrosine kinase signaling pathway. Endocrinology, 142, 3405-3413.

[214] Papiernik-Berkhauer E (1970) Etude en double aveugle d'un medicament prevenant la survenue prematurée de l'accouchement chez des femmes 'a risque eleve' d'accouchement premature. In Edition Schering, Serie IV, fiche 3.pp. 65-68.

[215] Pavletic AJ, Wolner-Hanssen P, Paavonen J, Hawes SE, and Eschenbach DA (1999) Infertility following pelvic inflammatory disease. Infect Dis Obstet Gynecol, 7, 145152.

[216] Penrose LS (1933) The relative effects of paternal and maternal age in Mongolism. J Genet, 27, 219-224.

[217] Penrose LS (1934) The relative aetiological importance of birth order and maternal age in Mongolism. Proc R Soc B Biol Sci, 115, 431-450.

[218] Phelan JP, Park YW, Ahn MO, and Rutherford SE (1990) Polyhydramnios and perinatal outcome. J Perinatol, 10, 347-350.

[219] Piersanti M and Lye SJ (1995) Increase in messenger ribonucleic acid encoding the myometrial gap junction protein, connexin-43, requires protein synthesis and is associated with increased expression of the activator protein-1, c-fos. Endocrinology, 136, 3571-3578.

[220] Pinborg A (2005) IVF/ICSI twin pregnancies: risks and prevention. Hum Reprod Update, 11, 575-593.

[221] Pinborg A, Lidegaard O, la Cour FN, and Andersen AN (2005) Consequences of vanishing twins in IVF/ICSI pregnancies. Hum Reprod, 20, 2821-2829. 
[222] Pirhonen J, Bergersen TK, Abdlenoor M, Dubiel M, and Gudmundsson S (2005) Effect of maternal age on uterine flow impedance. J Clin Ultrasound, 33, 14-17.

[223] Ralph SG, Rutherford AJ, and Wilson JD (1999) Influence of bacterial vaginosis on conception and miscarriage in the first trimester: cohort study. BMJ, 319, 220-223.

[224] Reddy UM, Wapner RJ, Rebar RW, and Tasca RJ (2007) Infertility, assisted reproductive technology, and adverse pregnancy outcomes: executive summary of a National Institute of Child Health and Human Development workshop. Obstet Gynecol, 109, 967-977.

[225] Rieder RF and Thomas L (1960) Studies on the mechanisms involved in the production of abortion by endotoxin. J Immunol, 84, 189-193.

[226] Romero R, Espinoza J, Mazor M, and Chaiworapongsa T (2004) The preterm parturition syndrome. In Critchely H, Bennett P, and Thornton S (eds) Preterm Birth. RCOG Press, London, pp. 28-60.

[227] Romero R, Gomez R, Mazor M, Ghezzi F, and Yoon BH (1997) The preterm labor syndrome. In Elder MG, Romero R, and Lamont RF (eds) Preterm labor. Churchill Livingstone, New York, NY, pp. 29-49.

[228] Romero R, Mazor M, Wu Y, Sirtori M, Oyarzun E, Mitchell M, and Hobbins J (1988a) Infection in the pathogenesis of preterm labor. Seminars in Perinatology, 12, 262-279.

[229] Romero R (1996) The child is the father of the man. Prenat Neonat Med, 1, 8-11.

[230] Romero R, Espinoza J, Mazor M, and Chaiworapongsa T (2004a) The preterm parturition syndrome. In Critchley C, Bennet P, and Thornton S (eds) Preterm Birth. RCOG Press, London, pp. 28-60.

[231] Romero R, Espinoza J, Chaiworapongsa T, and Kalache K (2002) Infection and prematurity and the role of preventive strategies. Semin Neonatol, 7, 259-274.

[232] Romero R, Espinoza J, Erez O, and Hassan S (2006a) The role of cervical cerclage in obstetric practice: can the patient who could benefit from this procedure be identified? Am J Obstet Gynecol, 194, 1-9.

[233] Romero R, Espinoza J, Kusanovic J, Gotsch F, Hassan S, Erez O, Chaiworapongsa T, and Mazor M (2006b) The preterm parturition syndrome. BJOG, 113 Suppl 3, 17-42.

[234] Romero R, Espinoza J, and Mazor M (2004b) Can endometrial infection/inflammation explain implantation failure, spontaneous abortion, and preterm birth after in vitro fertilization? Fertil Steril, 82, 799-804.

[235] Romero R, Espinoza J, Mazor M, and Chaiworapongsa T (2004c) The preterm parturition syndrome. In Critchley $\mathrm{H}$, Bennett $\mathrm{P}$, and Thornton S (eds) Preterm Birth. RCOG Press, London, pp. 28-60.

[236] Romero R, Gonzalez R, Sepulveda W, Brandt F, Ramirez M, Sorokin Y, Mazor M, Treadwell MC, and Cotton DB (1992) Infection and labor. VIII. Microbial invasion of the amniotic cavity in patients with suspected cervical incompetence: prevalence and clinical significance. Am J Obstet Gynecol, 167, 1086-1091.

[237] Romero R, Kusanovic JP, Chaiworapongsa T, and Hassan SS (2011) Placental bed disorders in preterm labor, preterm PROM, spontaneous abortion and abruptio placentae. Best Pract Res Clin Obstet Gynaecol, 25, 313-327.

[238] Romero R, Manogue KR, Mitchell MD, Wu YK, Oyarzun E, Hobbins JC, and Cerami A (1989) Infection and labor. IV. Cachectin-tumor necrosis factor in the amniotic fluid of women with intraamniotic infection and preterm labor. Am J Obstet Gynecol, 161, 336-341. 
[239] Romero R, Mazor M, and Gomez R (1993) Cervix, incompetence and premature labor. Fetus, 3, 1 .

[240] Romero R, Mazor M, Munoz H, Gomez R, Galasso M, and Sherer DM (1994) The preterm labor syndrome. Ann N Y Acad Sci, 734, 414-429.

[241] Romero R, Mazor M, Wu YK, Sirtori M, Oyarzun E, Mitchell MD, and Hobbins JC (1988b) Infection in the pathogenesis of preterm labor. Semin Perinatol, 12, 262-279.

[242] Romero R, Munoz H, Gomez R, Ramirez M, Araneda H, Cutright J, Wolf N, Cotton D, and Fidel PL (1994) Antibiotic therapy reduces the rate of infection-induced preterm delivery and perinatal mortality. In p. 390.

[243] Romero R, Quintero R, Oyarzun E, Wu YK, Sabo V, Mazor M, and Hobbins JC (1988) Intraamniotic infection and the onset of labor in preterm premature rupture of the membranes. Am J Obstet Gynecol, 159, 661-666.

[244] Romero R, Sepulveda W, Baumann P, Yoon BH, Brandt F, Gomez R, Mazor M, Sorokin Y, and Cotton D (1993) The preterm labor syndrome: Biochemical, cytologic, immunologic, pathologic, microbiologic, and clinical evidence that preterm labor is a heterogeneous disease. In p. 288.

[245] Romero R, Sirtori M, Oyarzun E, Avila C, Mazor M, Callahan R, Sabo V, Athanassiadis AP, and Hobbins JC (1989) Infection and labor. V. Prevalence, microbiology, and clinical significance of intraamniotic infection in women with preterm labor and intact membranes. Am J Obstet Gynecol, 161, 817-824.

[246] Rosen T, Kuczynski E, O'Neill LM, Funai EF, and Lockwood CJ (2001) Plasma levels of thrombin-antithrombin complexes predict preterm premature rupture of the fetal membranes. J Matern Fetal Med, 10, 297-300.

[247] Rosen T, Schatz F, Kuczynski E, Lam H, Koo AB, and Lockwood CJ (2002) Thrombinenhanced matrix metalloproteinase-1 expression: a mechanism linking placental abruption with premature rupture of the membranes. J Matern Fetal Neonatal Med, 11, 11-17.

[248] Rossi AC and D'Addario V (2011) Neonatal outcomes of assisted and naturally conceived twins: systematic review and meta-analysis. J Perinat Med.

[249] Rouse DJ, Caritis SN, Peaceman AM, Sciscione A, Thom EA, Spong CY, Varner M, Malone F, Iams JD, Mercer BM et al (2007) A trial of 17 alpha-hydroxyprogesterone caproate to prevent prematurity in twins. N Engl J Med, 357, 454-461.

[250] Rudolph MI, Reinicke K, Cruz MA, Gallardo V, Gonzalez C, and Bardisa L (1993) Distribution of mast cells and the effect of their mediators on contractility in human myometrium. Br J Obstet Gynaecol, 100, 1125-1130.

[251] Rush RW, Isaacs S, McPherson K, Jones L, Chalmers I, and Grant A (1984) A randomized controlled trial of cervical cerclage in women at high risk of spontaneous preterm delivery. Br J Obstet Gynaecol, 91, 724-730.

[252] Rust OA, Atlas RO, Jones KJ, Benham BN, and Balducci J (2000) A randomized trial of cerclage versus no cerclage among patients with ultrasonographically detected second-trimester preterm dilatation of the internal os. Am J Obstet Gynecol, 183, 830-835.

[253] Rust OA, Atlas RO, Reed J, van GJ, and Balducci J (2001) Revisiting the short cervix detected by transvaginal ultrasound in the second trimester: why cerclage therapy may not help. Am J Obstet Gynecol, 185, 1098-1105. 
[254] Ruutiainen K and Seppala M (1991) Polycystic ovary syndrome: evolution of a concept. Curr Opin Obstet Gynecol, 3, 326-335.

[255] Sakai M, Shiozaki A, Tabata M, Sasaki Y, Yoneda S, Arai T, Kato K, Yamakawa Y, and Saito S (2006) Evaluation of effectiveness of prophylactic cerclage of a short cervix according to interleukin-8 in cervical mucus. Am J Obstet Gynecol, 194, 14-19.

[256] Salafia CM, Lopez-Zeno JA, Sherer DM, Whittington SS, Minior VK, and Vintzileos AM (1995) Histologic evidence of old intrauterine bleeding is more frequent in prematurity. Am J Obstet Gynecol, 173, 1065-1070.

[257] Salem YS, Levy A, Wiznitzer A, Holcberg G, Mazor M, and Sheiner E (2011) A significant linear association exists between advanced maternal age and adverse perinatal outcome. Arch Gynecol Obstet, 283, 755-759.

[258] Sanchez-Ramos L, Kaunitz AM, and Delke I (2005) Progestational agents to prevent preterm birth: a meta-analysis of randomized controlled trials. Obstet Gynecol, 105, 273-279.

[259] Sarno JL, Schatz F, Lockwood CJ, Huang ST, and Taylor HS (2006) Thrombin and interleukin-1beta regulate HOXA10 expression in human term decidual cells: implications for preterm labor. J Clin Endocrinol Metab, 91, 2366-2372.

[260] Savva GM, Walker K, and Morris JK (2010) The maternal age-specific live birth prevalence of trisomies 13 and 18 compared to trisomy 21 (Down syndrome). Prenat Diagn, 30, 57-64.

[261] Scarpitta AM and Sinagra D (2000) Polycystic ovary syndrome: an endocrine and metabolic disease. Gynecol Endocrinol, 14, 392-395.

[262] Schieve LA, Meikle SF, Ferre C, Peterson HB, Jeng G, and Wilcox LS (2002) Low and very low birth weight in infants conceived with use of assisted reproductive technology. N Engl J Med, 346, 731-737.

[263] Schwartz D and Mayaux MJ (1982) Female fecundity as a function of age: results of artificial insemination in 2193 nulliparous women with azoospermic husbands. Federation CECOS. N Engl J Med, 306, 404-406.

[264] Shebl O, Ebner T, Sir A, Sommergruber M, and Tews G (2009) The role of mode of conception in the outcome of twin pregnancies. Minerva Ginecol, 61, 141-152.

[265] Shennan A, Crawshaw S, Briley A, Hawken J, Seed P, Jones G, and Poston L (2006) A randomised controlled trial of metronidazole for the prevention of preterm birth in women positive for cervicovaginal fetal fibronectin: the PREMET Study. BJOG, 113, 65-74.

[266] Shevell T, Malone FD, Vidaver J, Porter TF, Luthy DA, Comstock CH, Hankins GD, Eddleman K, Dolan S, Dugoff L et al (2005) Assisted reproductive technology and pregnancy outcome. Obstet Gynecol, 106, 1039-1045.

[267] Shynlova OP, Oldenhof AD, Liu M, Langille L, and Lye SJ (2002) Regulation of c-fos expression by static stretch in rat myometrial smooth muscle cells. Am J Obstet Gynecol, 186, 1358-1365.

[268] Shyy JY and Chien S (2002) Role of integrins in endothelial mechanosensing of shear stress. Circ Res, 91, 769-775.

[269] Sills ES, Perloe M, and Palermo GD (2000) Correction of hyperinsulinemia in oligoovulatory women with clomiphene-resistant polycystic ovary syndrome: a review of therapeutic rationale and reproductive outcomes. Eur J Obstet Gynecol Reprod Biol, 91, 135-141. 
[270] Skarnes RC and Harper MJ (1972) Relationship between endotoxin-induced abortion and the synthesis of prostaglandin F. Prostaglandins, 1, 191-203.

[271] Sladek SM, Westerhausen-Larson A, and Roberts JM (1999) Endogenous nitric oxide suppresses rat myometrial connexin 43 gap junction protein expression during pregnancy. Biol Reprod, 61, 8-13.

[272] Slattery MM and Morrison JJ (2002) Preterm delivery. Lancet, 360, 1489-1497.

[273] Smith GC, Pell JP, and Walsh D (2001) Pregnancy complications and maternal risk of ischaemic heart disease: a retrospective cohort study of 129,290 births. Lancet, 357, 2002-2006.

[274] Sobel JD (2000) Bacterial vaginosis. Annu Rev Med, 51:349-56., 349-356.

[275] Stein ZA (1985) A woman's age: childbearing and child rearing. Am J Epidemiol, 121, 327-342.

[276] Stephenson CD, Lockwood CJ, Ma Y, and Guller S (2005a) Thrombin-dependent regulation of matrix metalloproteinase (MMP)-9 levels in human fetal membranes. J Matern Fetal Neonatal Med, 18, 17-22.

[277] Stevenson CS, Glasko A.J., and Gillespie EC (1951) Treatment of typhoid in pregnancy with chloramphenicol (chloromycetin). JAMA, 146, 1190.

[278] Takeda Y and Tsuchiya I. (1953) Studies on the pathological changes caused by the injection of the Shwartzman filtrate and the endotoxin into pregnant rabbits. Jap J Exper Med, 21, 9-16.

[279] Taylor AE (1998) Polycystic ovary syndrome. Endocrinol Metab Clin North Am, 27, 877-902, ix.

[280] Ticconi C and Lye SJ (2002) Placenta and fetal membranes in human parturition and preterm delivery--a workshop report. Placenta, 23 Suppl A:S149-52., S149-S152.

[281] To MS, Alfirevic Z, Heath VC, Cicero S, Cacho AM, Williamson PR, and Nicolaides KH (2004) Cervical cerclage for prevention of preterm delivery in women with short cervix: randomised controlled trial. Lancet, 363, 1849-1853.

[282] To MS, Palaniappan V, Skentou C, Gibb D, and Nicolaides KH (2002) Elective cerclage vs. ultrasound-indicated cerclage in high-risk pregnancies. Ultrasound Obstet Gynecol, 19, 475-477.

[283] Tognoni G, Ferrario L, Inzalaco M, and Crosignani PG (1980) Progestagens in threatened abortion. Lancet, 2, 1242-1243.

[284] Tough S, Benzies K, Fraser-Lee N, and Newburn-Cook C (2007) Factors influencing childbearing decisions and knowledge of perinatal risks among Canadian men and women. Matern Child Health J, 11, 189-198.

[285] Tough S, Benzies K, Newburn-Cook C, Tofflemire K, Fraser-Lee N, Faber A, and Sauve $\mathrm{R}$ (2006) What do women know about the risks of delayed childbearing? Can J Public Health, 97, 330-334.

[286] Tzima E, del Pozo MA, Shattil SJ, Chien S, and Schwartz MA (2001) Activation of integrins in endothelial cells by fluid shear stress mediates Rho-dependent cytoskeletal alignment. EMBO J, 20, 4639-4647.

[287] Ugwumadu A, Manyonda I, Reid F, and Hay P (2003) Effect of early oral clindamycin on late miscarriage and preterm delivery in asymptomatic women with abnormal vaginal flora and bacterial vaginosis: a randomised controlled trial. Lancet, 361, 983-988. 
[288] Ugwumadu AH (2002) Bacterial vaginosis in pregnancy. Curr Opin Obstet Gynecol, $14,115-118$.

[289] Verstraelen H, Goetgeluk S, Derom C, Vansteelandt S, Derom R, Goetghebeur E, and Temmerman M (2005) Preterm birth in twins after subfertility treatment: population based cohort study. BMJ, 331, 1173.

[290] Vidaeff AC and Ramin SM (2006) From concept to practice: the recent history of preterm delivery prevention. Part II: Subclinical infection and hormonal effects. Am J Perinatol, 23, 75-84.

[291] Vintzileos AM, Ananth CV, Smulian JC, Scorza WE, and Knuppel RA (2002) The impact of prenatal care in the United States on preterm births in the presence and absence of antenatal high-risk conditions. Am J Obstet Gynecol, 187, 1254-1257.

[292] Vogel I, Glavind-Kristensen M, Thorsen P, Armbruster FP, and Uldbjerg N (2002) Srelaxin as a predictor of preterm delivery in women with symptoms of preterm labour. BJOG, 109, 977-982.

[293] Vogel I, Salvig JD, Secher NJ, and Uldbjerg N (2001) Association between raised serum relaxin levels during the eighteenth gestational week and very preterm delivery. Am J Obstet Gynecol, 184, 390-393.

[294] Wang YA, Sullivan EA, Black D, Dean J, Bryant J, and Chapman M (2005) Preterm birth and low birth weight after assisted reproductive technology-related pregnancy in Australia between 1996 and 2000. Fertil Steril, 83, 1650-1658.

[295] Watts DH, Eschenbach DA, and Kenny GE (1989) Early postpartum endometritis: the role of bacteria, genital mycoplasmas, and Chlamydia trachomatis. Obstet Gynecol, 73, 52-60.

[296] Watts DH, Krohn MA, Hillier SL, and Eschenbach DA (1990) Bacterial vaginosis as a risk factor for post-cesarean endometritis. Obstet Gynecol, 75, 52-58.

[297] Watts DH, Krohn MA, Hillier SL, and Eschenbach DA (1992) The association of occult amniotic fluid infection with gestational age and neonatal outcome among women in preterm labor. Obstet Gynecol, 79, 351-357.

[298] Weghofer A, Klein K, Stammler-Safar M, Barad DH, Worda C, Husslein P, and Gleicher N (2009) Severity of prematurity risk in spontaneous and in vitro fertilization twins: does conception mode serve as a risk factor? Fertil Steril, 92, 2116-2118.

[299] Weiss G, Goldsmith LT, Sachdev R, Von HS, and Lederer K (1993) Elevated firsttrimester serum relaxin concentrations in pregnant women following ovarian stimulation predict prematurity risk and preterm delivery. Obstet Gynecol, 82, 821828.

[300] Wilson JD, Ralph SG, and Rutherford AJ (2002) Rates of bacterial vaginosis in women undergoing in vitro fertilisation for different types of infertility. BJOG, 109, 714-717.

[301] Wing ES and Troppoli D.V. (1930) The intrauterine transmission of typhoid. JAMA, 95, 405.

[302] Wisborg K, Ingerslev HJ, and Henriksen TB (2010b) In vitro fertilization and preterm delivery, low birth weight, and admission to the neonatal intensive care unit: a prospective follow-up study. Fertil Steril, 94, 2102-2106.

[303] Wisborg K, Ingerslev HJ, and Henriksen TB (2010a) IVF and stillbirth: a prospective follow-up study. Hum Reprod, 25, 1312-1316. 
[304] Wright VC, Schieve LA, Reynolds MA, and Jeng G (2003) Assisted reproductive technology surveillance--United States, 2000. MMWR Surveill Summ, 52, 1-16.

[305] Wright VC, Schieve LA, Reynolds MA, Jeng G, and Kissin D (2004) Assisted reproductive technology surveillance--United States, 2001. MMWR Surveill Summ, $53,1-20$.

[306] Wu WX, Ma XH, Yoshizato T, Shinozuka N, and Nathanielsz PW (1999) Differential expression of myometrial oxytocin receptor and prostaglandin $\mathrm{H}$ synthase 2, but not estrogen receptor alpha and heat shock protein 90 messenger ribonucleic acid in the gravid horn and nongravid horn in sheep during betamethasone-induced labor. Endocrinology, 140, 5712-5718.

[307] Yemini M, Borenstein R, Dreazen E, Apelman Z, Mogilner BM, Kessler I, and Lancet M (1985) Prevention of premature labor by 17 alpha-hydroxyprogesterone caproate. Am J Obstet Gynecol, 151, 574-577.

[308] Yogev Y, Melamed N, Bardin R, Tenenbaum-Gavish K, Ben-Shitrit G, and BenHaroush A (2010) Pregnancy outcome at extremely advanced maternal age. Am J Obstet Gynecol, 203, 558-7.

[309] Zahl PA and Bjerknes C (1943) Induction of decidua-placental hemorrhage in mice by the endotoxins of certain gram-negative bacteria. Proc Soc Exper Biol Med, 54, 329332.

[310] Zaib-un-Nisa S, Ghazal-Aswad S, and Badrinath P (2003) Outcome of twin pregnancies after assisted reproductive techniques--a comparative study. Eur J Obstet Gynecol Reprod Biol, 109, 51-54.

[311] Zlatnik FJ, Cruikshank DP, Petzold CR, and Galask RP (1984) Amniocentesis in the identification of inapparent infection in preterm patients with premature rupture of the membranes. J Reprod Med, 29, 656-660. 


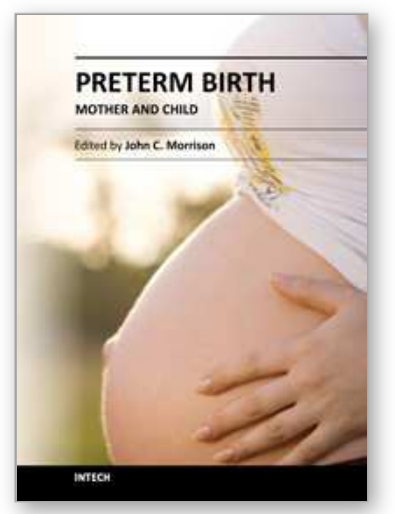

\author{
Preterm Birth - Mother and Child \\ Edited by Dr. John Morrison
}

ISBN 978-953-307-828-1

Hard cover, 368 pages

Publisher InTech

Published online 27, January, 2012

Published in print edition January, 2012

While there are many studies and books regarding preterm birth, both the obstetric and in the neonatal/pediatric literature, what is missing is the integration of data from obstetrics through neonatal course and into pediatrics as the neonate transverses childhood. A continued dialogue between specialties is essential in the battle against preterm birth in an attempt to relieve the effects or after-effects of preterm birth. For all of our medical advances to date, preterm birth is still all too common, and its ramifications are significant for hospitals, families and society in general.

\title{
How to reference
}

In order to correctly reference this scholarly work, feel free to copy and paste the following:

Offer Erez, Ruth Beer-Weisel, Tal Rafaeli-Yehudai, Idit Erez-Weiss and Moshe Mazor (2012). Assisted Reproduction and Preterm Birth, Preterm Birth - Mother and Child, Dr. John Morrison (Ed.), ISBN: 978-953307-828-1, InTech, Available from: http://www.intechopen.com/books/preterm-birth-mother-and-child/assistedreproduction-and-preterm-birth

\section{INTECH}

open science | open minds

\section{InTech Europe}

University Campus STeP Ri

Slavka Krautzeka 83/A

51000 Rijeka, Croatia

Phone: +385 (51) 770447

Fax: +385 (51) 686166

www.intechopen.com

\section{InTech China}

Unit 405, Office Block, Hotel Equatorial Shanghai

No.65, Yan An Road (West), Shanghai, 200040, China

中国上海市延安西路 65 号上海国际贵都大饭店办公楼 405 单元

Phone: +86-21-62489820

Fax: +86-21-62489821 
(C) 2012 The Author(s). Licensee IntechOpen. This is an open access article distributed under the terms of the Creative Commons Attribution 3.0 License, which permits unrestricted use, distribution, and reproduction in any medium, provided the original work is properly cited. 